\title{
EL DERECHO AL AGUA EN LAS NUEVAS CONSTITUCIONES DE MARRUECOS (2011) Y TÚNEZ (2014)
}

JUAN JOSÉ RUIZ RUIZ 
SUMARIO

I. INTRODUCCIÓN: EL DERECHO AL AGUA EN PERSPECTIVA COMPARADA. II. LA NATURALEZA DEL DERECHO AL AGUA COMO DERECHO EMERGENTE. III. LA PROGRESIVA RETIRADA DEL DERECHO MUSULMÁN COMO RÉGIMEN JURÍDICO DE BASE DEL AGUA EN MARRUECOS Y TÚNEZ. IV. LAS PECULIARIDADES DEL DERECHO DE AGUAS EN TÚNEZ Y EN MARRUECOS: 1. Marruecos. 2. Túnez. V. LA TARIFICACIÓN DEL SERVICIO DE ABASTECIMIENTO COMO HERRAMIENTA DE RESPETO AL CONTENIDO DEL DERECHO AL AGUA: 1. La tarificación en Marruecos anterior a la nueva Constitución. 2. La tarificación en Túnez antes de la constitucionalización del derecho al agua. VI. EL RECONOCIMIENTO DEL DERECHO AL AGUA EN LAS NUEVAS CONSTITUCIONES DE MARRUECOS (2011) Y TÚNEZ (2014). VII. EL MARCO INSTITUCIONAL DE LA GESTIÓN, PLANIFICACIÓN Y EXPLOTACIÓN DEL USO DEL AGUA: 1. Marruecos. 2. Túnez. VIII. LAS DIFICULTADES EN LA EFECTIVIDAD DEL DERECHO AL AGUA TRAS LAS NUEVAS CONSTITUCIONES: 1. Marruecos. 2. Túnez. 


\title{
EL DERECHO AL AGUA EN LAS NUEVAS CONSTITUCIONES DE MARRUECOS (2011) Y TÚNEZ (2014)
}

\author{
JUAN JOSÉ RUIZ RUIZ*
}

\section{INTRODUCCIÓN: EL DERECHO AL AGUA EN PERSPECTIVA COMPARADA}

Ausente de los textos constitucionales hasta tiempos recientes ${ }^{1}$, el derecho al agua, o más bien de acceso al agua potable, antes que un derecho fundamental ha ido adquiriendo carta de naturaleza como un derecho humano. Así, en sus estadios iniciales cabe mencionar el Comentario General n. ${ }^{\circ} 15$ del Comité de Derechos Económicos, Sociales y Culturales de Naciones Unidas (2002), sobre el Plan de Acción del Mar del Plata (1977); la Convención de Naciones Unidas para la Eliminación de todas las Formas de Discriminación contra la Mujer (1979); la Convención sobre Derechos de los Niños (1989); y la Declaración de Dublín sobre el Agua y al Desarrollo Sostenible (1992).

Pero donde encuentra una formulación más clara es en la resolución 15/9 de 30 de septiembre de 2010 del Consejo de Derechos Humanos sobre el derecho al agua establece en su artículo 3 que «el derecho fundamental al agua potable y al abastecimiento se deriva del derecho a un nivel de vida adecuado y que es indisociable del derecho al mejor estado de salud física y mental posible, así como del derecho a la vida y la dignidad; y en el artículo 6 reafirma que «los

* Profesor Titular de Derecho Constitucional. Universidad de Jaén. Departamento de Derecho Público. Edificio D3, dependencia 259. Campus Las Lagunillas, s/n., 23071, JAÉN. ORCID: 0000-0003-3375-6405. URL: ujaen.academia.edu/JuanJoséRuizRuiz Email: jjruiz@ujaen.es.

${ }^{1}$ Cfr. Tommaso Edoardo Frosini, «Dare un diritto agli assetati», Analisi Giuridica dell'Economia, 1/2010, Giugno, p. 31. 
Estados tienen la responsabilidad primordial de garantizar el pleno disfrute de todos los derechos humanos, y que el hecho de delegar de la prestación de servicios de agua potable y/o abastecimiento a un tercero no exime al Estado de sus obligaciones en materia de derechos humanos».

La Organización Mundial de la Salud, adoptó asimismo en 2011 una declaración sobre «Agua potable, abastecimiento y salud» (WHA 64/24, mayo de 2011), en la que se afirma que el derecho humano al agua y al abastecimiento «habilita a todos, sin discriminación, a disponer para su uso personal y doméstico de un agua y de un abastecimiento que sean suficientes, sin riesgo, aceptables, accesibles físicamente y abordables».

A nivel regional, tanto la Carta Africana sobre los Derechos y Bienestar del Niño (1990) como el Protocolo de la Carta Africana de Derechos Humanos y de los Pueblos relativo a los derechos de la mujer en África (2003) contienen obligaciones expresas respecto de los derechos humanos relacionados con el acceso al agua potable y el saneamiento. También la Carta Árabe de Derechos Humanos (2004) reconoce el derecho de toda persona a disfrutar del más alto nivel de vida posible, para lo cual los Estados deben garantizar la nutrición básica y el suministro de agua potable para todos, junto con sistemas de saneamiento adecuados (art. 39).

Las dos nuevas Constituciones de Marruecos y Túnez pasan a engrosar ese constitucionalismo del agua que encuentra sus estandartes especialmente en América Latina ${ }^{2}$ y África. El derecho al agua se está consolidando poco a poco en nuevas constituciones (África del Sur, Colombia, República Democrática del Congo, Gambia, Panamá, Uruguay, Venezuela, Zambia, etc.). En Ecuador y las Maldivas (2008), la Constitución reconoce el derecho al agua como un derecho humano fundamental. Kenia, la Constitución de 2010 reconoce el derecho a una vivienda adecuada, el derecho a estándares de un nivel razonable de saneamiento y el derecho al agua potable. En 2004 la Constitución de Uruguay pasa a definir el agua como un derecho natural esencial para la vida y el acceso al agua potable como un derecho humano fundamental estableciendo la gestión social y sostenible de los recursos hídricos del país, cuya planificación y control se someten a un proceso participativo y cuya gestión corresponde en exclusiva a los poderes públicos. De igual modo, la Constitución de Ecuador de 2008 reconoce los recursos naturales y entre ellos el agua, como bienes comunes, al proclamar en su art. 1, párrafo tercero, que, «los recursos naturales no renovables del terri-

\footnotetext{
${ }^{2}$ Sobre este continente, cfr. LuCA MezzetTI, «Il diritto all'acqua negli ordinamenti dei Paesi latinoamericani: evoluzioni recenti e prospettive», Diritto Pubblico Comparato ed Europeo, 2012, 2, pp. 553-565.
} 
torio del Estado pertenecen a su patrimonio inalienable, irrenunciable e imprescriptible». En su art. 12 constitucionaliza «el derecho humano al agua», al que se define como «fundamental e irrenunciable» y este mismo precepto corrobora el régimen jurídico que para todos los recursos naturales contempla el art. 1, al disponer que «el agua constituye patrimonio nacional estratégico de uso público, inalienable, imprescriptible, inembargable y esencial para la vida». De manera análoga se tutela otra necesidad vital al reconocer el derecho de «personas y colectividades» al «acceso seguro y permanente a alimentos sanos, suficientes y nutritivos». La doctrina ecuatoriana entiende que del contenido constitucional del derecho al agua se deriva una prelación de usos del agua 1) para el ser humano, 2) para la soberanía alimentaria, 3) para asegurar el ciclo vital del agua y 4) para actividades productivas. También las Constituciones de Guatemala (art. 128), Panamá (art. 118) y Ecuador (art. 23) han constitucionalizado el derecho al agua. En Bolivia la Constitución de 2009 en su art. 16.c.1 afirma que «toda persona tiene el derecho al agua y a la alimentación», declaración que completa el art. 20, al disponer que «toda persona tiene derecho de acceso universal e igual al servicio de agua potable (...) El acceso al agua constituye un derecho humano que no puede ser objeto de concesión y privatización». Una de las formulaciones más acabadas se encuentra en la Constitución de México que, tras la reforma de 2011, dispone en su art. 4 que «Toda persona tiene derecho al acceso, disposición y saneamiento de agua para consumo personal y doméstico en forma suficiente, salubre, aceptable y asequible. El Estado garantizará este derecho y la ley definirá las bases, apoyos y modalidades para el acceso y uso equitativo y sustentable de los recursos hídricos». A su vez, en Sudáfrica, el art. 27 c. 1 b) de la Constitución de 1996 reconoce que «toda persona tiene derecho de acceso al alimento y agua suficientes».

En Europa la consagración constitucional del derecho al agua se ha intentado en varias ocasiones en Bélgica, en un intento por incorporar nuevas generaciones de derechos como el derecho de acceso a internet o el derecho a la energía ${ }^{3}$. También en Francia el reconocimiento del derecho al agua ha sido objeto de diversas iniciativas parlamentarias desde 2013 que no han prosperado. Tal vez por ello su reconocimiento a nivel constitucional solo ha sido parcial y por vía hasta ahora jurisprudencial, puesto que ha sido en la decisión del Conseil Constitutionnel n. ${ }^{\circ} 2015-470$ de 29 de mayo de 2015, que resolvía una QPC (question prioritaire de constitutionnalité) planteada por una empresa adjudicataria (SAUR SAS), donde se ha reconocido que la prohibición de cortes de agua es

\footnotetext{
${ }^{3}$ Proposition de révision de l'article 23, alinéa 3, de la Constitution, en vue de le compléter par un $7 .^{\circ}$ garantissant le droit à l'eau, Doc. parl., Sénat, 2014, n. ${ }^{\circ}$ 6-36/1.
} 
conforme a la Constitución ${ }^{4}$. A nivel legislativo se encuentra reconocido en el art. 1 de la Ley n. ${ }^{\circ}$ 2006-1772, de 30 de diciembre de 2006, sobre el agua y medios acuáticos, en el que se dispone que «cada persona física, para su alimentación e higiene, tiene el derecho de acceder al agua potable en condiciones económicamente aceptables para todos». A nivel jurisprudencial, el Tribunal de Justicia de la Unión Europea en una sentencia de 2012 reconocía el suministro de agua como una prioridad, especialmente en lo que ser refiere al impacto sobre la salud y la vida de la población ${ }^{5}$. En España, el Estatuto de la Comunidad de Valencia (2006), el de la Comunidad de Aragón (2007) y el de Castilla-La Mancha (2007) garantizan el derecho de las personas a tener un suficiente suministro de agua de calidad. En el estado de Sinaloa, en México, su constitución (2008) reconoce el derecho al agua y al saneamiento.

\section{LA NATURALEZA DEL DERECHO AL AGUA COMO DERECHO EMERGENTE}

A la categoría difusa de los derechos emergentes pertenecen nuevos derechos que tienen en común proteger un mínimo existencial o unas condiciones dignas de vida. Este novedoso grupo de derechos estaría forjando la aparición de una nueva generación de derechos que tendría como denominador común el satisfacer necesidades humanas básicas. Se trataría de derechos de carácter no intencional y cuyo objeto es remediar situaciones de carencia o privación de las que se puede seguir un daño o padecimiento ${ }^{6}$. Así, cabe mencionar, entre otros, el derecho a la salud y a las prestaciones sanitarias, el derecho a una vivienda digna, el derecho a una renta mínima, el derecho a la alimentación o el derecho al agua ${ }^{7}$.

${ }^{4}$ En efecto, el órgano de la jurisdicción constitucional consideró que la conocida como Ley Brottes $n .^{\circ}$ 2013-312 no contradecía la libertad de empresa, la libertad contractual ni el principio de igualdad ante la ley o el de igualdad ante los cargos públicos. Sin embargo, el Conseil Constitutionnel ha evitado en esta decisión reconocer un derecho constitucional al agua al fundamentar la garantía de acceso al agua en el objetivo de valor constitucional de una vivienda digna. $C f r$. CAROLE NIVARD, «La garantie d'un accès à l'eau devant le Conseil Constitutionnel», AJDA, L'Actualité Juridique Droit Administratif, núm. 30, 2015, p. 1705.

5 STJUE (Gran Sala) de 11 de septiembre 2012, Symvouliotis Epikrateias (Grecia).

${ }^{6}$ Cfr. María José AÑón Roig, Necesidades y derechos. Un ensayo de fundamentación, Centro de Estudios Constitucionales, Madrid, 1994, p. 266.

7 Un catálogo de estos derechos se encuentra en la Declaración de Monterrey de 2 de noviembre de 2007, especialmente en su segunda Parte, donde se consagran cincuenta derechos humanos emergentes divididos en seis partes: democracia igualitaria, plural, paritaria, participativa, solidaria, garantista. 
Ahora bien, no ha faltado quien, como Ignatieff, ha observado un efecto paradójico en la transformación en derechos fundamentales de toda expectativa individual, ya que su virtualidad sería la de debilitar los derechos puesto que los reduciría a un papel casi retórico. $\mathrm{Al}$ respecto considera Ignatieff que los derechos deberían reservarse para proteger lo que es justo y no lo que simplemente produce un bien $^{8}$. En esta línea vale la pena también señalar que el derecho constitucional al agua no debe confundirse con el derecho de aguas, ni tampoco con el derecho de los cursos de agua.

Superadas las primeras formulaciones en el ámbito internacional de la optimización del aprovechamiento de los cauces de agua de ciertos ríos trasfronterizos, se viene entendiendo que la categoría jurídico-dogmática idónea para la protección y tutela del acceso al agua es la de un derecho fundamental. Hay quien sin embargo ha considerado que con ello se da entrada a una suerte de «iusnaturalismo hídrico» que puede ir en perjuicio de la sostenibilidad del propio recurso natural cuyo uso se pretende garantizar ${ }^{9}$. Así, la Conferencia de Naciones Unidas sobre el agua del Mar de la Plata de 1977 utilizaba una fórmula cercana a la de posteriores textos constitucionales, al proclamar que «todos tienen derecho de acceder al agua potable en cantidad y calidad correspondiente a las respectivas necesidades». Su contenido abarcaría de entrada el acceso a un agua sana y en cantidad suficiente y además el uso de servicios higiénico-sanitarios ${ }^{10}$. El intento de dotar de un nuevo perfil dogmático el acceso y el consumo del agua como bien jurídico protegido ha venido sobre todo exigido por reflexiones doctrinales que han puesto de manifiesto las limitaciones de la tradicional configuración del agua como un bien demanial. Se ha sugerido en este sentido que es mucho más idónea para expresar su conexión con los derechos fundamentales la categoría dogmática de los bienes comunes. En especial dicha categoría permitiría englobar ciertos aspectos esenciales del agua como objeto de un derecho fundamental, entre los que se cuentan el carácter intergeneracional y los derechos de las generaciones futuras, así como disociar en su tutela el aspecto posesorio de la vertiente de la gestión ${ }^{11}$.

Cabe plantearse si esta solución doctrinal puede ser diferenciada de quienes postulan el derecho al agua como un derecho colectivo. Su configuración como

${ }^{8}$ Cfr. Michael Ignatieff, La Révolution des droits, Boréal, Montreal, 2001, p. 30.

9 Cfr. Danilo Zolo, «L'accesso all'acqua come diritto sociale $e$ diritto collettivo», Diritto Pubblico, Gennaio-aprile, 1/2005, p. 131. p. 26.

${ }^{10}$ Cfr. Giuseppe Romeo, L'acqua. Scenari per una crisi, Rubbettino, Catanzaro, 2005,

${ }^{11}$ Cfr. Ugo Mattei y Alessandra Quarta, L'acqua e suo diritto, Ediesse, Roma, 2014, p. 41 . 
derecho colectivo tiene inevitablemente un componente temporal, por cuanto implica una permanencia colectiva en un lugar con unas condiciones geográficas y ambientales que deben garantizar unas condiciones de vida y salud sostenibles para el futuro. En este sentido el carácter colectivo del derecho al agua debe más bien identificarse con un derecho de las generaciones futuras.

Una primera observación debe ir dirigida al objeto de protección del nuevo derecho. Si se parte de la idea de que el objeto de protección y las expectativas que se pretenden tutelar con el derecho al agua pueden ser de hecho sin dificultad reubicados dentro del contenido de otros derechos igualmente fundamentales. Tal cosa sucede por ejemplo con el derecho a la vida, el derecho a la salud, el derecho a una vivienda digna o el derecho al medioambiente sano. El agua es necesaria para producir alimentos, para asegurar la higiene ambiental, para procurase medios de subsistencia. De este modo, la interdependencia dichos derechos nos indica el carácter indivisible de los derechos fundamentales. Los textos constitucionales por lo general no recogen expresamente el estatuto jurídico aplicable al agua en tanto que cosa, sino que solo emplean principios que más bien condicionan su gestión. Por ejemplo, en Francia el agua quedaría comprendida dentro del patrimonio común de los seres humanos que se consagra en la Carta del Medio Ambiente.

Es necesario también a partir de estas figuras para diferenciar el objeto de protección del derecho al agua, del bien jurídico protegido. En efecto, mientras que el objeto protegido por el derecho al agua parece que no ha de ser otro que el abastecimiento y la salubridad del agua, el bien jurídico que se trata de preservar se entiende que ha de ser la vida y a la salubridad de las condiciones de vida. Hasta ahora el agua había venido siendo protegida como un bien demanial, de manera que sustrayéndola de la propiedad privada y del tráfico jurídico se posibilitaba un uso de ese mismo bien por todos, de manera que el uso de unos no impida el uso por los demás interesados ${ }^{12}$. A esta concepción clásica en la que el agua era una res extra commercium, que no podía ser objeto de apropiación, ni de contratos, ni transmisible mortis causa por los usuarios, se vinieron a superponer las técnicas de la utilización privativa de los bienes demaniales, así como el

12 En Marruecos el principio de demanialidad de las aguas aparece con el art. 1 del dahir de 1 de septiembre de 1914 sobre el demanio público y sobre todo de la modificación introducida a este texto por el dahir de 8 de noviembre de 1919, en cuya Exposición de Motivos se decía que «para asegurar una utilización más metódica de las riquezas hidráulicas el presente dahir incorpora al demanio público las aguas que el dahir de 1 de julio de 1914 había dejado a la libre disposición de los particulares». Como excepción, el dahir de 1 de julio 1914, creó el dominio público hidráulico, ya que su artículo 2 mantiene los derechos de propiedad de usufructo o uso legal del agua adquiridos antes de su publicación. 
de la utilización individual. Con el reconocimiento de usos privativos sin embargo se pueden ocasionar perturbaciones del bien que pueden afectar al uso del resto de usuarios. Dichos usos han recibido un régimen similar a un ius in re aliena. Pero fuera de esos usos especiales, el uso común o general del agua es un auténtico derecho subjetivo a la utilización de dicho bien por parte de todos los ciudadanos que por lo pronto supone que se pueda reaccionar contra medidas de prohibición o de exclusión del uso o disfrute del mismo ${ }^{13}$.

$\mathrm{Al}$ igual que otros derechos sociales, especialmente los derechos prestacionales, el derecho al agua no se comprende sin relacionarlo con las doctrinas jurídicas de la escasez o del mínimo de necesidades vitales que, desde Hume, permea los derechos humanos promovidos desde las instancias internacionales ${ }^{14}$. De hecho, no existe especial dificultad en admitir este tipo de derechos vinculados a las necesidades básicas vitales y existenciales como derechos de carácter humanitario que integran el patrimonio jurídico común de la Humanidad ${ }^{15}$. De este modo, el derecho al agua entronca con un imperativo moral y de equidad que tiene por principal consecuencia asignar al Derecho una función distribuidora conforme a criterios de justicia. Pero no es únicamente la escasez el fundamento legitimador de este nuevo derecho, sino que ofrece una segunda vertiente que entronca con la eficacia del Derecho, lo que supone desplazar los términos del problema fuera del terreno de la validez o de la justicia, en tanto que no se trata ya de corregir desigualdades, sino en el terreno de la realidad fáctica que puede operar como límite o barrera de derechos fundamentales si se desvincula la economía de criterios morales desligados del bien común ético ${ }^{16}$.

Así como desde los presupuestos que legitiman los derechos sociales no hay obstáculo para que el derecho al agua entre en las nuevas cartas de derechos, no cabe decir lo mismo respecto a su configuración como derecho subjetivo. Al

13 Así, Embid Irujo, entiende que los usos privativos del agua deben quedar excluidos de todo eventual derecho subjetivo al agua, que debería quedar circunscrito a los usos comunes. Incluso entiende Embid que un derecho subjetivo al agua no es incompatible incluso con acabar con la gratuidad de los usos comunes mediante el establecimiento de un precio. $C f$ r. Antonio EmBID Irujo, «El derecho al agua en el marco de la evolución del derecho de aguas», en ID. (dir.), El derecho al agua, Thomson-Aranzadi, Cizur Menor, 2006, pp. 42 y 52.

${ }^{14}$ Cfr. Gregorio Peces-Barba, «Escasez y derechos humanos», en José M. ${ }^{a}$ Sauca (ed.), Problemas actuales de los derechos fundamentales, Madrid, Universidad Carlos III-BOE, 1994, p. 201.

15 Cfr. Ingo Wolfgang SARLET, «Los derechos sociales a prestaciones en tiempos de crisis», en Miguel Ángel Presno Linera (coord.), Crisis económica y atención a las personas y grupos vulnerables, Procuradora General del Principado de Asturias-Universidad de Oviedo, Oviedo, 2012, p. 2.

${ }^{16}$ Cfr. G. Peces-Barba, «Escasez y derechos humanos», en José María Sauca (ed.), Problemas actuales de los derechos fundamentales, op. cit., p. 202. 
respecto, el derecho al agua no puede sustraerse a las objeciones que se suelen plantear a aquellos derechos que presentan una dimensión económica relevante. En concreto los problemas derivados de la escasez de agua pueden determinar que el destinatario de la norma o mandato prestacional no se encuentre en condiciones de prestar lo que la norma le impone, pues puede encontrarse en situaciones o períodos en los que la existencia real del objeto de este derecho lo convierte en indisponible o impracticable.

La declaración del agua como patrimonio común de los seres humanos o de la nación no necesariamente repercute en su carácter demanial, de forma que no se deriva de ello que siempre que se declara como bien común el agua tenga un régimen de propiedad pública. La calificación de bien o patrimonio común viene siendo entendido como un régimen intermedio que obliga a una gestión sostenible del agua, sin perjuicio de su estatuto jurídico.

Sin embargo, la constitucionalización de un derecho al agua pretende proteger al agua incluso de los usos o aprovechamientos privados. En efecto, la lógica que parece imperar en la construcción doctrinal del derecho al agua, es la de sustraer este bien de su afectación a otros usos particulares así como la de evitar su patrimonialización. De ahí que hayan formulado propuestas encaminadas a dotar el agua de un estatus que supere el de bien público demanial, y que lo convierta en un bien común. Primero, asegurando que frente a una colisión con los derechos patrimoniales, los extra-patrimoniales primen. Desde este punto de vista todos aquellos bienes demaniales afectados al abastecimiento y consumo del agua podrían en razón de su inalienabilidad no ser objeto de concesión para su gestión privada, no pudiendo entrar de este modo entre los bienes patrimoniales públicos afectados a otros usos. La afectación se convierte así en determinante de un régimen jurídico más restrictivo, no bastando la titularidad pública de un bien para poder ser cedido a la gestión privada ${ }^{17}$. Se trataría en segundo lugar de garantizar a través de estos bienes el principio de salvaguardia intergeneracional de su uso, reconociendo una titularidad difusa sobre ellos, de manera que en sentido estricto quedarían así sustraídos a la titularidad estatal, no pudiendo ser considerados un género de la especie de los bienes públicos. El acceso privado a estos bienes, así como la posibilidad de que sean objeto de concesión debe limitarse y, en todo caso, condicionándolo a la compatibilidad de la misma con la preservación del bien para generaciones futuras. En congruencia con ello

17 Cfr. Pierre Dardot y Christian Laval, Commun. Essai sur la révolution au XXIe siècle, La Deouverte, Paris, 2015, p. 265. 
se debe reconocer una acción de tutela para garantizar el derecho a usar del agua haciendo cesar los impedimentos a su ejercicio ${ }^{18}$. De este modo se consigue proteger los bienes según su utilidad y vincularlos a la tutela de derechos de la persona y al interés público general.

El contenido del derecho al agua no solo puede desdoblarse en un derecho social de prestación o en un mandato a los poderes públicos, sino que debe comprender asimismo una faceta que es también consustancial a la mayoría de derechos prestacionales y que consiste en velar por la continuidad en el abastecimiento del agua, su salubridad y su uso racional. No solo por tanto el derecho al agua encierra la prestación de un servicio público, sino que su contenido impone la obligación a los poderes públicos de planificar y adoptar aquellas medidas encaminadas a tener garantizado el abastecimiento incluso en épocas de sequía.

De otra parte, el reconocimiento de un derecho al agua plantea la cuestión de si cabe incardinarlo entre los derechos subjetivos o si está a medio camino entre un derecho social y la prestación de un servicio público esencial, siendo así que su materialización se encuentra sujeta al pago de tasas y precios públicos. Los parámetros de exigibilidad de un servicio público esencial o de interés general son en este sentido distintos de los que rigen para los derechos fundamentales. Pese a ello, no debe desconocerse la evolución experimentada en la concepción, normativa y doctrinal, de los servicios de interés económico general y la centralidad que ocupan en la actualidad los derechos de los usuarios, a los que se debe garantizar el acceso universal y un alto nivel de calidad, seguridad, accesibilidad económica e igualdad de trato ${ }^{19}$.

Desde un ángulo muy distinto, a la constitucionalización del derecho al agua se pueden extender algunas de las consideraciones que habitualmente se dirigen al pretendido derecho a la alimentación, o más en general, a la garantía de un mínimo vital. En efecto, la comunitarización de un bien y la garantía de una accesibilidad universal a su consumo parecen en contradicción con su mercantilización y comercio. Tiene por ello sentido imponer tasas sobre las actividades de comercialización del agua, como las que por ejemplo ha previsto la legislación francesa para la producción o comercialización del agua embalada o embotellada, o para la importación de agua destinada a ser comercializada, además de contemplar un impuesto sobre la cifra de negocio de los distribuidores del agua comer-

${ }^{18}$ Cfr. Edoardo Reviglio, «Per un riforma del regime giuridico dei beni pubblici. Le proposte della Commissione Rodotà», Politica del Diritto, Volume XXXIX, n. ${ }^{\circ}$ 3, Settembre, 2008 , p. 535.

19 Así lo establece, por ejemplo, en el ámbito de la Unión Europea, el art. 1 del Protocolo 26 del Tratado de Lisboa de 2007. 
cializada $^{20}$. Como alternativa al impuesto sobre la cifra de facturación de la comercialización de agua, se podría considerar la de imponer una tasa al consumo de agua potable de la red de abastecimiento.

En todo caso la constitucionalización del derecho al agua debiera llevar aparejado un contenido mínimo garantizado constitucionalmente que habría de contemplar la preservación de los ecosistemas y el medio ambiente relacionados con el agua para asegurar el uso sostenible de los recursos hídricos; el acceso sostenible a servicios de agua potable y saneamiento para todos; lo que significa que la respuesta a las necesidades humanas básicas es satisfactoria cualitativa y cuantitativamente, asequible económica y socialmente aceptable. Dentro de dicho contenido mínimo se perfila como materia especialmente susceptible de desarrollo legislativo la tarificación adaptada a los recursos económicos y la subvención o ayudas para pagar la factura del consumo doméstico indispensable para una vida digna. La tarifa se convierte de este modo en el mejor indicador de la efectividad del derecho al agua ${ }^{21}$.

Distinto de dicho contenido mínimo son las políticas públicas encaminadas hacia la sostenibilidad de un recurso escaso. En este sentido, parece indispensable que dichas políticas tiendan al uso eficiente y económicamente viable de agua en los sectores productivos; que implica la interrupción del uso del agua como una herramienta de subsidio, la mejora de la recuperación de las aguas residuales tratadas y la implementación de una regulación por incentivos en función del rendimiento y finalmente la preservación y el desarrollo del patrimonio intangible relacionado con el agua. Además de dicho contenido el suministro de agua es un servicio público que debe cumplir con los principios de rendición de cuentas, la transparencia y la participación y no debe ser administrado por intereses privados.

\section{LA PROGRESIVA RETIRADA DEL DERECHO MUSULMÁN COMO RÉGIMEN JURÍDICO DE BASE DEL AGUA EN MARRUECOS Y TÚNEZ}

La antigüedad de la reglamentación de los usos del agua en el Norte de África y en Medio Oriente es quizás la mejor expresión de la necesidad de la protección de un bien que esencial para la vida y que condiciona a su vez el desarrollo de una

\footnotetext{
${ }^{20}$ Artículo L. 1320-3 del Código de Salud Pública.

${ }^{21}$ Cfr. Roberto Louvin, La dimensione sociale ed ecologica del diritto all'acqua, en SiLvio Gambino, Diritti sociali e crisi economica. Problemi e prospettive, Giappichelli, Torino, 2015, p. 535.
} 
comunidad $^{22}$. Los modelos de explotación y de conducción del agua han tenido un gran peso, no solo en el desarrollo social y económico, sino también en la historia política de todo el Maghreb, en la que la colonización favoreció un proceso dinamizador que arranca con los primeros proyectos de agricultura industrial.

Debe precisarse que, aunque en ambas Constituciones al Derecho musulmán no se le reconozca como fuente del Derecho, careciendo en principio de fuerza normativa, el reconocimiento del Islam como constante nacional en Marruecos o como religión del Estado en Túnez, inspira todavía parte de la legislación. En efecto, si bien a priori la consagración del Islam como religión oficial del Estado marca una diferencia respecto de otros países en los que la sharia ha obtenido el reconocimiento de fuente del Derecho, siendo tradicionalmente considerado éstos Estados teocráticos y los primeros Estados confesionales, los Preámbulos de ambas Constituciones expresan el compromiso del pueblo a las enseñanzas del Islam (Túnez) o la religión islámica como principio y valor inmutable de la Constitución. De ahí resulta una normatividad axiológica del Derecho islámico, que orienta ciertas decisiones del legislador, de forma que la legislación positiva ha procedido a una cierta codificación del derecho musulmán sobre todo en lo que se refiere al estatuto personal, el régimen de los bienes inmuebles en manos muertas (babus o waqf) y los de propiedad privada (melk) ${ }^{23}$.

Del mismo modo, ha sido ante todo el derecho musulmán, como cuerpo normativo de la religión oficial en Marruecos y Túnez, el que había venido asegurando la disponibilidad de agua a todos los miembros de la comunidad. Sin embargo ambos países han procedido a desarraigar el régimen del agua del Derecho musulmán: en Marruecos a partir de la Ley 10-95 y en Túnez ya desde la colonización (especialmente a partir de la aprobación en 1933 del Decreto de 5 de agosto de 1933, sobre regulación de la conservación y utilización de las aguas de dominio público refundiendo los textos que lo modificaban y completaban $)^{24}$. En efecto, en ambos países, a diferencia de otros sectores del ordenamiento, el legislador no ha incluido referencias al derecho musulmán

${ }^{22} C f r$. Barbara Anagnostou-Canas, «La réglementation de l'usage agricole de l'eau dans l'Egypte hellénistique et romaine», Journées d'études de l'association pour l'étude des droits de l'Egypte ancienne, EPHE, Paris, 2009.

${ }^{23}$ Cfr. Mohammed Mounqit, «Marginalité de la charia et centralité de la Commanderie des croyants: le cas paradoxal du Maroc», en BAudouin Dupret, La charia aujourd'bui. Usages de la référence au droit islamique, La Découverte, Paris, 2012, p. 145.

${ }^{24}$ No obstante la demanialización del agua se llevó a cabo en ambos países respetando el reconocimiento y conservación de los derechos adquiridos, que en todo caso quedaban precisados y regulados. Cfr. JEAN-JACQues PéRennès, L'eau et les hommes au Maghreb, Karthala, Paris, 1993 , p. 120 . 
como fuente del derecho a diferencia de lo que ocurre en otros sectores del Derecho de bienes, como ocurre por ejemplo en Marruecos con el art. 1 de la ley 39-08 sobre derechos reales, ni tampoco se ha inspirado en sus preceptos como ocurre en cambio con el Código Penal, o con el código de obligaciones y contratos (copia del tunecino) y los productos financieros islámicos ${ }^{25}$. Es más, la ley 10-95 sobre el agua rehusó utilizar la terminología propia del derecho musulmán como las zonas de protección que según la jurisprudencia malekita reciben el nombre de harim. Tampoco se refiere a instituciones centrales al derecho musulmán de aguas como el $\operatorname{chirb}^{26}$ o la $c h a f a^{27}$. El apartamiento del derecho musulmán en 1995 por parte del legislador marroquí conduce a una simplificación de los tipos de propiedad del agua que pasan a ser dos (demanial, que engloba casi todo tipo de agua y la derivada del reconocimiento de derecho adquiridos), frente a los múltiples que admite el Derecho musulmán.

Una de las consecuencias de someter las instituciones hidrológicas del derecho musulmán al Derecho estatal fue la de incorporar todos los babous o bienes en manos muertas existentes sobre el agua, es decir, todas aquellos manantiales, fuentes, infraestructuras hidráulicas, molinos o canales que se hubieran constituido como bien religioso para beneficio de la comunidad. Se completaba así un proceso paralelo de estatalización de instituciones y doctrinas del Islam de las escuelas doctrinales para inaugurar un Islam oficial, gestionado por el Ministerio de habous $^{28}$. Aun así, la vigilancia del cumplimiento de las obligaciones de los

25 Desde 2007 los productos islámicos autorizados por el Banco Central de Marruecos para que puedan sean comercializados son la Mourabaha (donde un Banco financia un proyecto a un empresario que aporta su trabajo y en el que los beneficios se comparten según lo pactado, pero las pérdidas solo son asumidos exclusivamente por el Banco participado (Rab el Mal), la Ijara (que es un tipo de arrendamiento bajo dos modalidades distintas según sea con o sin compromiso de compra al término del plazo acordado) y la Moucharaka (que también conoce dos modalidades y que tiene por objeto la participación de un Banco en las pérdidas y beneficios de un proyecto según un porcentaje predeterminado).

${ }^{26}$ El chirb consiste en el derecho de usar el agua para el riego de tierras. Cuando se trata de grandes masas el derecho de chirb se reconoce universalmente, mientras que el uso del agua de riberas o pantanos se restringe a que no se ocasione un perjuicio a la comunidad. Cfr. Allal EL Menouar, Aspects institutionnels et reglementaires des ressources en eau au Maroc, Rabat, 2009, p. 11.

${ }^{27}$ El derecho de chafaa es el derecho de saciar la sed que se reconoce a todo musulmán o el de los no musulmanes a usar el agua de fuente, pozos o cursos de agua para saciar su sed o la de sus animales. Cfr. JeAn-JaCQues Pérennès, L'eau et les hommes au Maghreb, Karthala, Paris, 1993, p. 122.

${ }^{28}$ Los bienes «habous» reciben este nombre por quedar inmovilizados por voluntad de su propietario, de forma que no pueden ser donados, ni vendidos sin que su precio no sea destinado a la limosna. En el Maghreb, estos bienes son gestionados directamente por los Estados a través de los Ministerios o de la Dirección de Asuntos Religiosos. 
propietarios de aguas privadas corresponde al Ministerio de asuntos islámicos si dichos derechos proceden de la constitución de un habous a favor de la administración $^{29}$.

Ahora bien, el Derecho musulmán mantiene su importancia en tanto en cuanto permanece como el derecho incorporado a la legislación sobre bienes inmuebles, de modo que en la medida en que el régimen sobre el agua era el mismo que el de los bienes inmobiliarios y en la medida en que la legislación marroquí sobre bienes inmobiliarios tiene por base el Derecho musulmán, éste y sus reglas de interpretación han conservado cierta importancia.

Similares consideraciones se deben hacer respecto Túnez, donde el Derecho musulmán tampoco es formalmente fuente del Derecho, pero goza de una fuerza material incontestable en ciertos sectores del ordenamiento ${ }^{30}$, como el derecho de sucesiones o el de familia si bien éste se aparta en ciertos aspectos como en la prohibición de la poligamia, el divorcio judicial o la tutela parental.

Los principios islámicos de gestión del agua que tradicionalmente han venido compartiendo Marruecos y Túnez son los pertenecientes a la tradición sunita de rito malekita que reconoce el derecho de saciar la sed a los tres tipos de agua (privativa, pública restringida y pública), a diferencia de la chií (que solo lo admite para el agua pública) ${ }^{31}$. El rito malekita considera propietario del agua solamente a quien ha cavado un pozo o una acequia. Sin embargo las reglas del rito malekita, muy deferentes con la propiedad privada, nunca han sido totalmente aplicadas en Marruecos, donde cada recurso hídrico ha estado muy ligado a la costumbre y organización de cada grupo humano, especialmente las tribus. Su importancia ha acabado por integrar la costumbre local como fuente principal del Derecho del agua junto a la jurisprudencia del chrâa como derecho musulmán local. En, la doctrina ha considerado que el rito malekita es el que más lejos ha ido en cuanto a extraer consecuencias jurídicas de la aceptación de la propiedad privada del agua ya que permite que el propietario de una fuente o manan-

${ }^{29}$ Los habous públicos una institución del Derecho musulmán por la que el propietario puede destinar bienes inmuebles destinados a obras piadosas o a fundaciones de interés general sin limitación de tiempo. Constituyen por tanto una suerte de bienes en manos muertas. La doctrina entiende que sin llegar a se poder considerarse propiedad del Estado, los bienes habous, en virtud de su afectación a una obra piadosa o de interés social, se someten a las régimen del demanio público, como sostienen autores como Eddahbi. Los habous en Marruecos tiene su fundamento jurídico en un dahir de 1913, que se inspira principalmente en el fiqh malekita. C fr. ABdelfattah EDDAHBI, Les biens publics en droit marocain, Editions Afrique Orient, Casablanca, 1992.

${ }^{30}$ Cfr. Slim Laghmani, «Droit musulman et droit positif: le cas tunisien», en AA. VV., Politiques législatives: Égypte, Tunisie, Algérie, Maroc, CEDEJ, Egypte-Soudan, 1994, p. 156.

${ }^{31}$ Cfr. J. Lapanne-Joinville, «Le régime des eaux en droit musulman (rite malékite)», Revue algérienne, tunisienne et marocaine de législation et jurisprudence, vol. 72, 1956, pp. 12-90. 
tial o de un pozo pueda disponer libremente del agua cuyo uso le pertenece privativamente, pudiendo donarla, venderla o alquilar su caudal ${ }^{32}$. Ello supone una modulación extrema al principio general de propiedad común de uso local que rige el Derecho musulmán ${ }^{33}$. Sin embargo, no ha de verse en este principio un equivalente al principio de demanialidad pública del agua si bien la utilidad general común.

También en Túnez, en la doctrina sunita, los derechos comunitarios sobre el agua se permiten solo para vastas extensiones de agua, de manera que se admite la apropiación particular solo en virtud de derechos de riego según el tipo de agua (de ríos de poco cauce, canales, pozos, fuentes o lluvia). Sin embargo estos principios no rigen de modo aislado, sino que se combinan especialmente desde los años 90 con principios y regulaciones de origen no religioso.

Aunque la jurisprudencia islámica no entre en detalles de la regulación estatal para establecer tarifas, ha elaborado algunos principios generales que sirven como criterio del precio del agua en todos los países musulmanes. Entre éstos cabe citar que el agua privada y restringida puede ser intercambiada como cualquier otro bien, que el agua pública no puede ser vendida, que el mercado determina los precios y en particular se acepta la intervención estatal en la fijación de los precios cuando la conducta de un operador cause daños al mercado o amenace el bienestar de la población ${ }^{34}$.

\section{LAS PECULIARIDADES DEL DERECHO DE AGUAS EN TÚNEZ Y EN MARRUECOS}

\section{Marruecos}

El régimen jurídico del agua en Marruecos sigue siendo todavía a día de hoy un compuesto de legislación y costumbres pero en el que el Derecho musulmán ha ido retrocediendo. En efecto, la legislación no ha conseguido desplazar las costumbres locales, hasta el punto que se puede afirmar que el derecho de aguas

32 Cfr. Allal El Menouar, Aspects institutionnels et reglementaires des ressources en eau au Maroc, Rabat, op. cit., p. 12.

33 Ese principio general se sustenta en dichos del Profeta Mahoma, según los cuales todo musulmán deben compartir los pastos, el agua y el fuego (Abu-Dawood, hadith 3470). Cfr. M. T. KAdOuRI, y. DJebBar y M. Nehdi, «Les droits sur l'eau et le commerce de l'eau: le point de vue de l'Islam», en Naser I. Faruqui, Asit K. Briswas et Murad J. Bino, La gestion de l'eau selon l'Islam, Karthala, Paris, 2003, p. 131.

${ }^{34}$ Cfr. M. T. Kadouri, y. Djebbar y M. Nehdi, «Les droits sur l'eau et le commerce de l'eau: le point de vue de l'Islam», ibid., p. 133. 
vive entre dos mundos: un mundo regido por el derecho positivo y un mundo regido por el derecho tradicional consuetudinario ${ }^{35}$. Ello es producto de que ha sido el legislador quien ha decidido respetar los derechos adquiridos en base a la costumbre $^{36}$. En efecto, especialmente en lo que se refiere a los usos agrícolas del agua, en el ámbito rural tradicionalmente han regido costumbres escritas que no hacen sino seguir la tradición oral, pues en la costumbre escrita no existen prescripciones sobre la propiedad del agua, de modo que son los jmâa quienes propician acuerdos entre usuarios del agua que eviten eventuales disputas posteriores ${ }^{37}$.

Especialmente es respecto al agua corriente tomada de un canal a través de una presa de derivación (uggug) y un canal de alimentación (targa) o una fuente (tagbbalut), donde la administración del agua sigue por tanto siendo hoy en día asunto de la comunidad de que se trate. En particular, es en relación al agua de las acequias entre aldeas, donde las reuniones de las jmaâ con los ksours afectados terminan en acuerdos escritos que comprometen a todas las comunidades de usuarios regantes del canal ${ }^{38}$. Así pues, la cuestión que se plantea en Marruecos a día de hoy es encontrar una forma de organización que refleje la diversidad de los sistemas de riego y diferentes formas de organización social. Entre estas formas de organización, la jmâa sigue ocupando un lugar de predilección no solo en lo que se refiere a las redes tradicionales de riego, sino también en lo que afecta a las infraestructuras de riego moderno, de modo que las asociaciones de usuarios de agua para la agricultura siguen dependiendo en gran medida de las jma $\hat{a}^{39}$.

35 Cfr. Fouzi Rherrousse, «Quelques remarques sur la codification de la loi sur l'eau», paper, p. 8.

${ }^{36}$ Cfr. Houria Tazi Sadeq, Du Droit de l'eau au droit à l'eau au Maroc et ailleurs, Eddif, Casablanca, 2006, p. 51.

37 La jmâ̂ es un comité de sabios que representa a todas las facciones que constituyen un grupo étnico o tribu. Se encuentra en todos los pueblos y se organiza sobre una base étnico-familiar. Su poder está moralmente reconocido y se aplica sin necesidad de imponerse por la fuerza. En materia de riego, el papel de las jmaâ fue y sigue siendo de una importancia fundamental.

${ }^{38}$ La jmầ actúa tanto a nivel local como instancia de proximidad de los regantes locales de una población y a nivel de grupos de poblaciones afectadas por el trazado del sistema de riego operado conjuntamente por este grupo de pueblos o ciudades. Es este papel unificador dentro de la comunidad más cercana de regantes de los pueblos y entre las comunidades agrupadas para la gestión de un sistema de riego, lo que sirve para hacer funcionar las Asociaciones de usuarios de aguas agrícolas (creadas por la ley n. ${ }^{\circ} 2-84$ ) sobre una base sólida de gestión. La jmaâ confía a nivel de cada pueblo la gestión de la red tradicional a una amazal designado por los regantes. Éste es responsable del control del riego en el pueblo y entre los pueblos alimentados por el canal de riego, que es objeto de un acuerdo entre ellos.

39 Cfr. Mohammed Raki, Thierry Ruf, en A. Richard, P. Caron, J. y Jamin, T. Ruf (eds.), Coordinations hydrauliques et justices sociales, Cirad, Montpellier, 2006, p. 16. 
A pesar de que la Ley 10-95 menciona la costumbre para regular la servidumbre de las aguas, su aplicación a derechos ya adquiridos ha encontrado como obstáculo la pervivencia de derechos locales consuetudinarios que en la práctica prevalecen sobre la propia ley ${ }^{40}$. La explicación reside en que la Ley del agua afecta a lo que cabe definir como grandes recursos hidráulicos, mientras que los recursos de menor escala siguen rigiéndose por la costumbre local, en especial en el ámbito rural en materia de riego. Nos referimos a los derechos de agua consuetudinarios que se recogen en textos escritos que establecen los denominados «Moulkias». En las zonas donde el agua es considerada como accesorio a la tierra un moulkia establecido en un fondo irrigado comprende necesariamente los derechos del agua afectados a él aunque no los mencione, ya que dichos derechos existen por la fuerza de la costumbre. En cambio, en las regiones donde existe un desmembramiento de la propiedad entre el suelo y el agua, esta no es obligatoriamente accesoria del fondo, de modo que el titular del agua no es el titular del suelo ${ }^{41}$.

En cuanto a la legislación, hasta el año 1995 en que se adopta la Ley 10-95, seguían rigiendo normas muy anticuadas, como el Acuerdo visirial de 26 de mayo de 1916 sobre protección de aguas destinadas al abastecimiento de agua de ciudades, aglomeraciones o campos militares, o el Dahir de 1 de agosto de 1925 sobre el régimen de aguas (el Código de aguas). Finalmente el reconocimiento del derecho de acceso al agua en el art. 31 de la Constitución de 2011 ha impulsado una nueva Ley del Agua, la Ley 36-15, promulgada mediante Dahir n. ${ }^{\circ} 1-16-113$ de 10 de agosto de 2016, casi a punto de finalizar la Legislatura.

La tradición del riego en los climas benignos y semiáridos con pluviometría media-baja resulta determinante para el desarrollo de las economías en el sector de la agricultura. Pero no solo es la pluviometría la que viene determinando los problemas en la gestión y garantía de acceso al agua, sino que junto a éste otra serie de condicionantes han venido a añadir de igual forma un progresivo replanteamiento en los modos de afrontar y combatir la escasez de agua asegurando al mismo tiempo el suministro ${ }^{42}$. Resulta sin duda de especial trascendencia a este

${ }^{40}$ Las materias en la que se han desarrollado los derechos consuetudinarios locales provienen de las divisiones tribales y se refieren a su seguridad, a los souks (mercados semanales), los moussems (festivales anuales), a la distribución del agua, a la gestión de los graneros colectivos (igoudars), las relaciones en el seno de las corporaciones artesanales, la represión de crímenes y delitos, la gestión de caminos comunes y las reglas de gestión y mantenimiento de los lugares de culto. C fr. LAHOUsSINE Bellouch, «L'Islam: source d'inspiration du droit marocain», Jurismat, n. . especial, 20014, p. 18

${ }^{41}$ Cfr. Mohamed Adnane, «Le régime juridique de l'eau au Maroc», Comunicación, mayojunio, 1989, p. 173.

42 El Alto Comisariado marroquí del agua, bosques y lucha contra la desertificación en un Informe de 2012 alertaba de que Marruecos habría traspasado la fase de escasez de agua para entrar 
respecto la evolución que se ha conocido en la concentración de población en las zonas urbanas ${ }^{43}$. Este fenómeno ha obligado a tener que captar los recursos de agua en zonas cada vez más lejanas.

Diversos programas nacionales han pretendido hacer frente a las penurias y escasez de agua que recurrentemente afronta el país ${ }^{44}$. Entre los aplicados en las últimas décadas cabe mencionar el programa PAGER (programa de abastecimiento de agua potable a las poblaciones rurales) que se inició en 1995 a raíz de los brotes de cólera durante el período de verano de 1988 - 1994. Se esperaba con él garantizar el suministro de 31.000 aldeas con 12 millones de personas con agua potable antes de 2010. Se pudo de este modo liberar a las mujeres y niños de la servidumbre de conducción de agua ${ }^{45}$. En 2005 se ponía en marcha otro programa, el PNA (Plan Nacional de Abastecimiento) que pretendía mejorar la protección cualitativa del agua, disminuyendo la contaminación del agua un $60 \%$ en 2010 y un $80 \%$ en 2015 , al tiempo que trataba de aumentar la tasa de acceso al agua a un $80 \%$ en 2015 .

La aplicación de la legislación sobre el agua ha venido sin embargo conociendo notables retrasos en su aplicación, especialmente debido a la ausencia de textos normativos para darle actuación y también debido a la falta de coherencia y coordinación entre las distintas instituciones nacionales y locales ${ }^{46}$.

en una fase de rareza de dicho bien. Según sus previsiones hacia 2020 la parte de agua por habitante se reducirá un $49 \%$, por lo que el volumen de agua por habitante se rebajaría hasta menos de $400 \mathrm{~m}^{3}$. De ahí que se marcara como objetivo acercar la tasa de depuración al $60 \%$ para 2020 frente al $13 \%$ del 2004 por ejemplo. Aun así, según datos de la ONU, 2,5 millones de personas viven todavía en Marruecos sin abastecimiento de agua.

${ }^{43} C f r$. M. Lahlou, «La variable démographique dans la politique économique marocaine», en J.-C. SAntucci (dir.), Le Maroc actuel, op. cit., p. 71.

${ }^{44}$ En Marruecos, las múltiples sequías y las plagas, con la consecuente escasez de grano, causaron carestías que fueron reiteradas a lo largo del siglo XIX, con crisis devastadoras como la de 1867-1869, la de 1878, y la de 1881-1883, en las que a la hambruna se sumaron las epidemias como el cólera, la viruela y el tifus. Como resultado, la población campesina abandonó los campos cultivables por el éxodo hacia la montaña a la búsqueda de agua. $C f r$. Mohamed Ennaji, «Crises de subsistances, endettement de la paysannerie et tranformations sociales. Le cas du Maroc au XIXe siècle», en Jean-Claude Santucci (dir.), Le Maroc actuel, Paris, Editions du CNRS, 1992, pp. 18 y 19.

45 De acuerdo con cifras oficiales del gobierno marroquí, el proyecto ha permitido un aumento de la tasa de acceso al agua en las zonas rurales del $14 \%$ en 1995 al $61 \%$ en 2004 y $77 \%$ en 2006. De acuerdo con los datos del censo, la tasa de acceso a las conexiones individuales en áreas rurales aumentó en un $10 \%$ en 1995 al $20 \%$ en 2004.

${ }^{46}$ Cfr. Annabelle Houdret, Les conflits autour de l'eau au Maroc: origines sociopolitiques et écologiques et perspectives pour une transformation des conflits, Thèse de doctorat, 2008, p. 30. 


\section{Túnez}

Túnez por su parte cuenta con los recursos más reducidos y escasos del Maghreb, sobre todo en lo que se refiere a las aguas subterráneas. El norte es considerado la reserva de agua de todo el país. Entre aguas de superficie y subterráneas representa un 59\% del total. En cambio, el centro representa un 18\% y el sur un $23 \%$ del total, siendo este último además de carácter no duradero.

En Túnez el agua cada vez más puede convertirse en un factor de freno del desarrollo socio-económico. Ante todo, porque en los próximos años el aumento de población va a terminar por tener que generar más producción agrícola con menos agua todavía ${ }^{47}$. Ese horizonte ha impulsado la búsqueda de fórmulas de optimización alternativas, tales como la reutilización de aguas usadas una vez tratadas, desalación de aguas salubres y del agua de $\operatorname{mar}^{48}$. Lo cierto es que el agua potable representa ya tan solo un $10 \%$ del uso total, disputándose su uso entre el riego, las necesidades domésticas e industriales ${ }^{49}$.

Justo en 2011 terminaba el programa que el gobierno de Ben Ali había puesto en marcha que giraba en torno a tres elementos: «i) la gestión y la conservación integrada del agua, ii) la eficiencia económica de la utilización del agua en el ámbito agrícola y iii) la restructuración de las instituciones y el refuerzo de capacidades en el sector del agua». La desalación es la solución aplicada para la gestión del agua en el sur de Túnez. La mayoría de unidades de desaladoras se localizan en efecto en el sur del país, con el inconveniente de que comporta un importante consumo de energía.

El precio del agua de uso agrícola se duplicó entre 1989 et 1996, mientras que las tasas sobre el agua del turismo se cuadruplicó respecto a la de uso agrícola. Precisamente una de las especificidades del agua en los países mediterráneos es la intensa estacionalidad estival del sector turístico, lo cual supone un desfase respecto al régimen natural del agua ya que la demanda se eleva a niveles máximos justo en la época en la que las precipitaciones son más

47 Para 2025 la población tunecina se estima que crecerá un 20\% hasta algo más de 12 millones, lo que implica un crecimiento en la demanda de agua de $3,5 \mathrm{~km}^{3}$. Con 13 millones de habitantes estimados para 2040, los recursos de agua por habitante decrecerán hasta 350 metros cúbico por año. En la actualidad se sitúa en los $430 \mathrm{~m}^{3}$ por año y habitante frente a los $3.000 \mathrm{~m}^{3}$ por ejemplo que tiene en la actualidad Francia por año y habitante. $C f r$. Daniel Zimmer, L'Empreinte eau: Les faces cachées d'une ressource vitale, Éditions Charles Leopold Mayer, 2013, p. 122 y 131.

48 Cfr. Mustapha Besbes, Jamel Chahed, Hedi Shayeb, Abdelkader Hamdane, «L'eau en Tunisie», en ID. Techniques de l'ingénieur Eau: propriétés, qualité, valeurs d'usage, Editions T. I., 2013, p. 2.

49 Cfr. D. Daniel Zimmer, L'Empreinte eau.., op. cit., p. 131. 
escasas. En la actualidad sin embargo las comunidades de regantes están siendo animadas por la legislación a reagruparse en colectivos participativos en ambos países. De este modo se pretende dar entrada a la propia población en la definición de nuevos modelos de gestión del agua, en especial en lo que se refiere a la denominada "pequeña hidráulica» ${ }^{50}$, que comprende los lagos de montaña, pantanos y otras estructuras de recarga de aguas subterráneas o aguas crecidas artificiales $^{51}$. Del mismo modo, se ha intentado poner en marcha en toda la región magrebí la recuperación del patrimonio arquitectónico hidráulico, en el que sobresalen las foggaras (denominación argelina para una especie de canales subterráneos de agua en la pendiente de los palmerales del desierto) ${ }^{52}$ y los meskat (una especie de impluvium) que se vendrían a añadir a los embalses de cuenca, lo que permitiría una distribución más minuciosa y colectiva del agua.

En Túnez el turismo no solo eleva la demanda de agua potable en las localidades de residencia turística (500 litros al día para un turista, muy por encima de la media de los nacionales 50 litros al día) sino que además lleva aparejadas actividades de servicios y de ocio de gran consumo de agua como es el caso de los campos de golf. En verano de 2013 la zona de Gran Túnez habitada por 2,5 millones de habitantes, ha sufrido por primera vez cortes de agua debido a la escasez. Entre 2012 y 2013, el consumo de agua se ha incrementado en un $12 \%$, debido al crecimiento de población urbana en torno a la capital.

${ }^{50}$ Cfr. Ridounane Berrhazi, «Évaluation de limpact de la participation paysanne dans les aménagements hydro-agricoles. Cas des associations des usagers des eaux agricoles de la petite et moyenne hydraulique des provinces du Nord marocain», en CHANTAL ASPE (dir.), De l'eau agricole à l'eau environnementale. Résistance et adaptation aux nouveaux enjeux de partage de l'eau en Méditerranée, Éditions Quae, Paris, 2012, pp. 253-270.

${ }^{51} C f r$. Gana y El Amrani, «Crise hydraulique au Maghreb: raréfaction de la ressource ou problèmes de gestion», Géocarrefour, vol. 81-1, 2006, p. 37.

52 En Marruecos se las conoce con el nombre de khettara y en Túnez con el nombre de kriga o también ngoual. Cfr. Boualem Remini, Bachir Achour Et Rabah KeCHad, «La foggara en Algérie: un patrimoine hydraulique mundial», Revue des sciences de l'eau / Journal of Water Science, vol. 23, n. ${ }^{\circ}$ 2, 2010, p. 106. Vid., asimismo, «L'eau et le Maghreb: un aperçu sur le présent de l'héritage et l'avenir», Rapport PNUD (Programme des Nations-Unies pour le Développement), 1986, pp. 131-143. 


\section{LA TARIFICACIÓN DEL SERVICIO DE ABASTECIMIENTO COMO HERRAMIENTA DE RESPETO AL CONTENIDO DEL DERECHO AL AGUA}

\section{La tarificación en Marruecos anterior a la nueva Constitución}

Se tiene asumido por la teoría económica desde hace ya bastante tiempo que, especialmente en tiempos de crisis económica, la tributación debe ser sustituida por la tarificación al coste real del servicio como método de su financiación. Se considera además que de este modo se obtienen mejores resultados desde el punto de vista de la distribución de recursos y desde el punto de vista de la equidad social, pues tratándose de servicios que anteriormente cabía clasificar dentro de los monopolios naturales, su característica fundamental es que la función del coste es subaditiva. De esta manera, el debate se sitúa en aplicar el coste marginal. Ahora bien, la fijación de una tarifa igual al coste marginal, cuando los rendimientos tengan una escala creciente, significa que la colectividad debe asumir el déficit estructural que genera este sistema. En consecuencia, si bien este tipo de tarificación soluciona el problema de la distribución de los recursos, sin embargo plantea un problema en cuanto a su equidad, dado que dicho déficit, si se quiere mantener la tarifa igual al coste marginal, tendrá que ser cubierto vía presupuestos del Estado, lo cual origina una redistribución del dinero de los contribuyentes en favor de los usuarios del servicio ${ }^{53}$.

Teniendo en cuenta estos principios, la tarificación del agua para uso doméstico e industrial en Marruecos ha sufrido una importante evolución. Queda ya lejos el modelo de tarifa uniforme aplicable a cualquier cantidad de agua y la tasa de abono al servicio, variable según el tamaño de la propiedad. Este modelo, propuesto por Freeman Clarke Coffin a principios del siglo Xx permitía aplicar una tarifa de consumo por debajo de su coste, pero aseguraba ingresos relativamente estables ${ }^{54}$. Hasta la independencia del país predominó este modelo de tarifa plana, combinado además con el doble sistema de suministro hasta entonces existente, que combinaba la alimentación de agua mediante fuentes públicas sin contador, con un sistema más moderno y urbano con contadores. Los problemas de la tarifa uniforme comenzaron a aflorar en el momento en que el crecimiento de núcleos poblacionales urbanos demandaba grandes inversiones para la movilización, captación y distribución del agua, lo cual se agravaba al no

53 Cfr. Mohammed Serghini, «La tarification des services de l'eau au Maroc», New Medit, n.1/2003, p. 6.

${ }^{54}$ Cfr. Ben Abdelfadel Abdelfadil, «Le secteur de l'eau potable: essai d'application d'une tarification au cout marginal,» Memoire du cycle superieur INSEA, Rabat, 1981, p. 26. 
diferenciar el sistema de tarifa uniforme entre zonas del territorio ni tampoco sectores de actividad. Además por definición, al aplicar la misma tarifa a cualquier tipo de consumo, era evidente que este modelo no incitaba precisamente al ahorro de agua. Gracias al Banco Mundial y a los estudios nacionales de tarificación del agua potable realizados periódicamente desde 1977, se impone el abandono del modelo anterior y se perfila un nuevo modelo, que pasa a ser disuasorio a partir de un nivel de consumo doméstico determinado, mientras que por contra se incentiva el consumo del agua de regadío 55 .

El nuevo modelo de tarificación perdura a lo largo de los años 80 y culmina en los años noventa, adoptando la tarificación progresiva basada en el coste marginal a largo plazo para favorecer la racionalización en el consumo, pero también la generalización del acceso al agua potable sin perjudicar a las poblaciones de menor renta. Se trata de una tarificación por tramos, que en el primer tramo establece una tarifa inferior al precio del metro cúbico, a fin de que la población de renta más baja pueda tener garantizado el acceso al agua potable. Este período coincide con la concesión de préstamos de fondos de inversión a la ONEP (Office National de l'Eau Potable) para financiar los grandes proyectos de infraestructuras hasta que en 1995 adquiere plena autonomía financiera. La tarificación de los usuarios domésticos se estructuraba en 4 tramos, ya que en 1982 se introduce un tercer tramo y el 1 de noviembre de 2000 se añade un cuarto tramo. En 1985 se establece además una sobretasa que desde el punto de vista financiero ha contribuido a extender el servicio de agua potable y de abastecimiento de 94 centros en 1985 hasta los 455 en $2006^{56}$.

La fluctuación de las tarifas entre 1977 y 2001 conoció dos períodos. Uno se ha caracterizado por la estabilidad en los precios, mientras que un segundo ha estado marcado por un alza en los precios para recuperarse del retraso acumulado. De media entre esos mismos años el precio del agua se elevó un $8 \%$, muy por debajo de los precios de productos básicos como el pan, el azúcar o la gasolina ${ }^{57}$. La elevación de precios de las tarifas no tuvo sin embargo el efecto desea-

55 En 1977 se produce el primer cambio en el modelo de tarificación, que contemplaba tres tarifas para el consumo doméstico: una tarifa social para pequeños consumidores (menos de $30 \mathrm{~m}^{3}$ / trimestre), tarifa al coste real para el tramo de $30-60 \mathrm{~m}^{3} /$ trimestre y una tarifa penalizadora para los grandes consumidores (más de $60 \mathrm{~m}^{3} /$ trimestre). El consumo industrial gozaba sin embargo de una tarifa preferente. Cfr. JeAn Jacques Pérennès, L'eau et les hommes au Maghreb, op. cit., p. 274.

${ }^{56}$ Cfr. Fatiha Belamari, «Gestion de l'eau au Maroc dans un système complexe et incertain», Tribuna del Agua, Zaragoza, 2008, p. 10.

57 Cfr. Mohamed Rhalloussi, «Tarification de l'eau potable au Maroc. Concepts, príncipes et methodologies», Revue H. T. E., núm. 124, Septembre-Décembre, 2002, p. 18. 
do debido a varios motivos. Uno de ellos fue el aumento de precios que tuvo lugar solo en las tarifas más bajas. Incluso la tarifa media más elevada alcanzó desproporciones desconocidas, situándose el precio de la tarifa del agua potable en un nivel quinientas veces más bajo que el litro de agua mineral ${ }^{58}$.

La privatización de los servicios de distribución del agua y de la electricidad en Marruecos se ha hecho bajo la fórmula de «gestión delegada». En un espacio de seis años (1997-2002), la delegación de servicio público del agua (y de la electricidad) afectaba al 50\% del volumen del agua distribuida en las grandes ciudades marroquíes por 17 operadores (13 régies locales y 4 operadores privados $)^{59}$.

El Estado justificaba este nuevo enfoque por la constatación de que los recursos hídricos del país eran ya un bien escaso y raro, lo cual obligaba a introducir nuevos modos de gestión que no podían seguir siendo los de la esfera pública y fuera del mercado. El Estado se decidió por la gestión privada por diversas razones, pero especialmente resultó decisivo el estatus político de las sociedades públicas. Estas sociedades (régies) de distribución de agua y de electricidad han estado bajo el mando de las autoridades políticas locales (cargos electos y también agentes de la autoridad) que han llevado a cabo una gestión caótica por la falta del pago de facturas.

La gestión delegada equivale aquí a la privatización del servicio, sin embargo la delegación del servicio público (DSP), eufemismo con el que se designa la privatización de servicios ${ }^{60}$, no ha resuelto numerosos de los distintos problemas del agua en el Maghreb que persisten bajo la gestión privada. Así, por ejemplo, los recursos de agua en explotación siguen siendo insuficientes, los nuevos recursos potenciales son escasos, lejanos y costosos de trasladar, las instalaciones de producción, tratamiento y almacenamiento se han quedado obsoletas, con falta de medios técnicos y financieros para su mantenimiento por lo que precisan de rehabilitaciones. Las redes de distribución necesitan rehabilitaciones y amplia-

58 Este nivel se alcanzó en 1997 cuando el precio del litro de agua era de 0,66 céntimos.

59 Cfr. Mehdi Lahlou, «La privatisation de l'eau au Maroc: premiers constats à partir de l'expérience de la Lyonnaise des Eaux à Casablanca», en Olivier Hoedeman et SAToko Kishiмото (coords.), L'eau, un bien public: alternatives démocratiques à la privatisation de l'eau dans le monde entier, Éditions Charles Léopold Mayer, Paris, 2010, p. 245.

${ }^{60}$ La gestión delegada se rige en Marruecos por el Dahir n. ${ }^{\circ} 1-06-15$ de 14 de febrero de 2006 y tiene como marco jurídico la ley n. ${ }^{\circ} 54.05$ sobre gestión delegada de servicios públicos, que regula aspectos como la definición del contrato de gestión delegada, los principios del servicio público, el equilibrio económico del contrato de gestión delegada, así como los modos y procedimientos de adjudicación de los contratos de gestión delegada, respetando los principios de concurso público y de transparencia, y por último regula los derechos y obligaciones del delegante y el delegatario. 
ciones muy costosas, al igual que las redes de abastecimiento (por no hablar de las estaciones depuradoras que se encuentran en un estado embrionario). Todo ello es muestra de las carencias de las empresas públicas.

La mejora en la gobernanza y gestión del agua a través de empresas privadas se ha revelado ineficaz sin una puesta a punto de las instalaciones, lo cual exige desembolsos e inversiones que no están al alcance de la administración local y que tampoco se podrían repercutir sobre los usuarios vía el aumento de los precios de consumo, dado el escaso nivel de renta. Si a eso se añade que toda multinacional debe generar beneficio para sus accionistas, la conclusión es que la gestión privada no es una solución por sí misma. El modelo de privatización seguido no ha tenido por ello en cuenta la pobreza de la población en el medio urbano. La recuperación total de costes se aplicó a todos los abonados, que además debieron soportar el aumento de tasas sobre consumo y abastecimiento de agua y electricidad especialmente a partir de 2006.

Iniciativas como las Operaciones de Abastecimientos Sociales (Opérations de Branchements Sociaux, OBS) que debían haber facilitado el acceso de los más pobres a la red, no dieron los resultados esperados. El coste de conexión a la red sigue siendo prohibitivo para una población que no sobrepasa en sus ingresos más de 1.600 euros al año de media. Desde 2005 otra medida ha sido la Iniciativa Nacional para el Desarrollo Humano (INDH), lanzada por el Rey Mohammed VI, ha permitido reducir la contribución financiera exigida a los hogares más desfavorecidos para acceder a los servicios de agua y saneamiento a niveles accesibles, mediante facilidades de pago ofrecidas por los operadores. Sin embargo, la diferencia entre la contribución de los hogares y el coste real de extensión de los servicios no es objeto de financiación pública finalista. Corresponde por tanto a las colectividades locales y territoriales en asociación con el operador, movilizar los fondos necesarios para salvar el desfase de financiación de los programas de conexión al abastecimiento. En ausencia de una ayuda pública para colmar de forma sistemática ese déficit de financiación, los programas de extensión del servicio en los barrios desfavorecidos difícilmente pueden generalizarse.

Los hogares beneficiarios requieren la conexión a los servicios y pagan una contribución predefinida, y se puede optar por pagar en efectivo o mensual durante 5 a 10 años, de acuerdo a las cantidades y condiciones estándar a nivel local en virtud de los convenios de la INDH. Los operadores se comprometen a reducir al mínimo el precio de la conexión y a prefinanciar inversiones para conectar a los hogares solicitantes. Después de la verificación independiente de las conexiones funcionales, el subsidio de OBA se paga al operador. La cuantía de la subvención OBA se define de antemano y tiene como objetivo reducir la diferencia entre la contribución solicitada para los hogares y la conexión de pre- 
cios optimizada ${ }^{61}$. Los proyectos piloto han hecho posible conectar 10.500 hogares al agua potable y más de 9.000 a la red de abastecimiento, ayudando a mejorar la vida de más de 50.000 personas $^{62}$.

En 2009 se elaboró la Estrategia Nacional del Agua, con la intención de diseñar un programa de gestión de la demanda de agua potable, turística e industrial. Como medidas se contemplaban la mejora de los rendimientos de las redes de distribución para alcanzar un $80 \%$ de media nacional hasta el 2020 contra el $71 \%$ actual; estimular los recursos para invertir en tecnologías de ahorro de agua, revisar el sistema tarifario, introducir mecanismos de auditoría del consumo de agua especialmente para los grandes consumidores (industrias y complejos turísticos).

\section{La tarificación en Túnez antes de la constitucionalización del derecho al agua}

En cuanto a la tarificación del agua de riego, desde 1990 se venía aplicando un aumento anual del $15 \%$ a la tarifa por $\mathrm{m}^{3}$ de agua para acelerar la recuperación de costes no amortizados y para el ahorro en el consumo. Asimismo, desde 1995 se introducen tres tipos de tarifas: La tarifa única, que es proporcional al volumen de agua consumida y tiene como finalidad que con el aumento progresivo de la tarifa del $\mathrm{m}^{3}$ de agua conseguir cubrir parcial o totalmente los gastos de funcionamiento de la red mediante la venta del agua. La tarifa dual prevé que los agricultores paguen una parte fija por un volumen mínimo y otra variable suplementaria al objeto de hacer soportar a los usuarios no solo el coste sino influenciar su consumo hacia el ahorro y la intensificación de cultivos en invierno. Por último la tarifa subvencionada consiste en la reducción del 50\% de la tarifa normal. Esta subvención está condicionada al cumplimiento de una serie de obligaciones, como la de seguir un itinerario técnico intensivo en especial en el cultivo de cereales. Esta tarifa se aplica también a las aguas usadas tratadas para el riego. También desde 1995 se venían aprobando subvenciones a los agricultores que hubiesen adoptado técnicas de ahorro del agua que iban desde el 40 al 60\% del total de la inversión según la superficie equipada con sistemas de ahorro.

${ }^{61}$ Así pues, la subvención se desembolsa al operador que ha prefinanciado las inversiones basadas en la conexión que se encuentra en el agua y el saneamiento a los hogares receptores. La subvención se desembolsa en dos etapas: el 60 por ciento de la subvención unitaria tras la realización de la conexión y el 40 por ciento tras comprobar que el servicio es satisfactorio durante seis meses.

${ }^{62}$ Cfr. Xavier Chauvot De Beauchêne, «Output-based Aid: extending water and sanitation services to the poor in peri- urban Morocco», World Bank, p. 4. 
El instrumento normativo sobre el que ha pivotado la política hidráulica previa a la adopción de la nueva Constitución de 2014 ha sido el Código de aguas de 1975 , al que se introdujeron modificaciones en $1987^{63}$, en $1988^{64}$ y en $2001^{65}$. En la reforma de noviembre 2001 se pretendió impulsar el ahorro de agua, el control de la demanda, y la calidad y cantidad del agua almacenada, así como la puesta en marcha del uso de agua no convencional mediante la desalinización del agua.

Los costes de producción y de distribución en los últimos años en Túnez se han visto sin duda afectados por el retraso en la revisión de la tarificación (2005-2010) lo que ha ocasionado unas pérdidas de 188 millones de dinares. El coste de producción y de conducción del m3 de agua potable hasta el grifo se situaba en 2011 en torno a los 716 céntimos de dinar (denominados millimes), de las que el ciudadano paga 565 millimes, lo cual significa que se cubre el $79 \%$ del coste.

Antes de la revolución de los jazmines la última actualización de tarifas tuvo lugar mediante dos arrêtés, uno del ministro de Agricultura, de recursos hidráulicos y pesca y otro arrêté del Ministro de Hacienda de 13 de julio de $2010^{66}$, introducía dos tarifas, una progresiva y otra uniforme. La progresiva se descompone en cinco niveles de precios según el volumen de consumo trimestral. La división en niveles perseguía tres objetivos: un objetivo de carácter social, ofreciendo la posibilidad a la capa de población de condición socio-económica más modesta acceder al agua potable a buen precio; un objetivo financiero, asegurando el equilibrio financiero de la SONEDE y permitir financiar los proyectos de explotación, renovación y desarrollo y un objetivo de eficiencia económica, ya que la tarificación progresiva por tramos permite un uso racional del agua.

La sociedad estatal de aguas (SONEDE) ha recurrido a la política tarifaria al objeto de poder rentabilizar la prestación de servicios a priori, y de paso sensibilizar al consumidor. La SONEDE ha optado también por la estrategia de la privatización del agua en línea con las directrices del Banco Mundial, que considera el agua como una mercancía que se puede vender y adquirir. La SONEDE ha puesto en marcha un Programa nacional de la inversión para la seguridad

${ }^{63}$ Ley n. ${ }^{\circ} 87-35$, de 6 de julio de 1987, de modificación de ciertos artículos del Código de Aguas, complementadas en 1997 mediante Decreto n. ${ }^{\circ}$ 97-2082 que establece las condiciones de ejercicio de la actividad de forraje del agua.

${ }^{64}$ Ley n. ${ }^{\circ} 88-94$, de 2 de agosto de 1988.

${ }^{65}$ Ley n. $.^{\circ} 2001-116$ de modificación del Código de aguas para crear un Consejo Nacional del Agua, posteriormente derogado por Decreto n. ${ }^{\circ}$ 2010-407, de 9 de marzo de 2010, de creación de un Consejo Nacional del Agua estableciendo sus objetivos, composición y modalidades de funcionamiento.

${ }^{66}$ JORT 56, de 13 de julio de 2010. 
hídrica, destinado a garantizar la seguridad del aprovisionamiento a pesar del veloz auge de la demanda y de los efectos del cambio climático. Según el Banco Mundial Túnez ha conseguido de este modo ofrecer uno de los mejores sistemas de acceso a los servicios de agua y de abastecimiento entre los países de la región de renta media.

\section{EL RECONOCIMIENTO DEL DERECHO AL AGUA EN LAS NUEVAS CONSTITUCIONES DE MARRUECOS (2011) Y TÚNEZ (2014)}

Tanto el texto constitucional marroquí como el tunecino se han caracterizado por una muy sensible ampliación del catálogo de derechos que no obedecía a su puesta al día, sino que en ambos casos se ha procedido al reconocimiento y garantía de derechos que vienen gozando de una dilatada tradición en el constitucionalismo democrático occidental, y que sin embargo se encontraban ausentes en las Constituciones anteriores a la "primavera árabe». La ampliación de los derechos constitucionales se ha visto acompañada de la introducción de cláusulas genéricas de limitación de los derechos muy dispares en uno y otro caso, pues en el caso marroquí la cláusula limitadora apela a conceptos culturales y comunitaristas, mientras que la cláusula genérica de limitación de derechos en la Constitución tunecina tiene un tenor que formalmente cabe adscribir al acquis internacional de los derechos humanos ${ }^{67}$.

En la nueva Constitución marroquí de 2011, figura por primera vez un capítulo dedicado a derechos constitucionales. Entre otros, han obtenido reconocimiento como nuevos derechos constitucionales la libertad de actuación de la sociedad civil (art. 12), el derecho de petición (art. 15), la igualdad en el ámbito civil, político, económico, social y cultural) entre hombres y mujeres (art. 19), el derecho a la vida (art. 20), el derecho a la seguridad personal, el derecho a la integridad física y mental y la prohibición de los tratos crueles, inhumanos o

${ }^{67}$ En el art. 49 de la Constitución tunecina se establece que «La ley determina las restricciones relativas a los derechos y libertades garantizados por la presente Constitución, y a su ejercicio, sin que ello pueda vulnerar su esencia. Estas restricciones no pueden ser aprobadas más que en caso de necesidad exigido por un Estado civil y democrático y con el objetivo de proteger los derechos de los demás, la seguridad pública, la defensa nacional, la salud pública o la moral pública y respetando el principio de proporcionalidad de las restricciones respecto al objetivo perseguido». En cambio, el art. 1 de la Constitución marroquí menciona la existencia de unas constantes nacionales basadas en elementos historicistas o culturalistas de la sociedad que pueden operar como factor de modulación o, mejor aún, como cláusula de limitación de los derechos que se impone como una restricción al legislador. 
degradantes que atenten a la dignidad (art. 22), la presunción de inocencia, el derecho de los detenidos a ser informados inmediatamente de los motivos de la detención y su derecho a guardar silencio y a tener asistencia letrada, la proscripción del racismo el odio y la violencia (art. 23), el derecho a la protección de la vida privada, la libertad artística y científica (art. 25), el derecho de acceso a la información y el derecho a la transparencia frente a la Administración y a las instituciones representativas (art. 27), la libertad de prensa (art. 28), el derecho de manifestación pacífica, el derecho de huelga (art. 29), el derecho de sufragio activo y pasivo (art. 30). En su art. 31, recoge en realidad lo que es un mandato a los poderes públicos para que movilicen recursos a fin de garantizar a todos los ciudadanos el acceso a una serie de prestaciones y recursos en condiciones de igualdad para su disfrute.

El texto constitucional marroquí de 2011 en su art. 31 recoge en realidad lo que es un mandato a los poderes públicos para que movilicen recursos a fin de garantizar a todos los ciudadanos el acceso a una serie de prestaciones y recursos en condiciones de igualdad para su disfrute. En un amplio listado se consagran distintos derechos sociales, que aparecen en una lista tasada, lo cual convierte el art. $31 \mathrm{CM}$ en una suerte de Título sobre derechos sociales. En cuanto al agua, el enunciado de dicho precepto, lo menciona en el mismo apartado que el derecho a un medioambiente sano y lo hace de un modo minimalista, de modo que el contenido constitucionalmente garantizado del derecho al agua parece limitarse al igual acceso a este recurso natural. Dispone en efecto el art. 31 que «el Estado, los establecimientos públicos y las colectividades territoriales actúan para la movilización de todos los medios disponibles para facilitar el igual acceso de ciudadanas y ciudadanos a las condiciones que les permitan disfrutar del derecho: de acceso al agua y a un ambiente sano». Así pues, y a diferencia de la Constitución tunecina, la fórmula marroquí no es tan abierta y parece excluir tanto una cantidad suficiente como la potabilidad del agua como integrantes de ese contenido mínimo, ya que lo que se garantiza constitucionalmente es el acceso al agua. Es patente además que se trata de un mandato que no se ha sido configurado como una obligación de resultado, dado que el encabezado del art. $31 \mathrm{CM}$ mandata a que se movilicen recursos por parte de los poderes públicos, lo que supone una obligación de hacer que debe orientar las políticas públicas. En virtud de esta naturaleza, cabe albergar dudas de que estemos ante un verdadero derecho subjetivo, sino que más bien se trata de un principio rector o de un objetivo de la política social. De ahí pueden derivarse consecuencias para la tutela constitucional de este supuesto derecho, dada la elasticidad del enunciado del art. $31 \mathrm{CM}$. 
En la Constitución tunecina de 2014 el Capítulo II está enteramente consagrado a los derechos y libertades comprendiendo 29 artículos (arts. 21 a 49), en los que se integran derechos de primera (arts. 21-37) $)^{68}$, de segunda (arts. 38-42) ${ }^{69}$ y de tercera generación (arts. 43-48) ${ }^{70}$, además de una cláusula general de limitación de los derechos (art. 49).

El art. 44 de la Constitución de Túnez de 2014 establece que «Está garantizado el derecho al agua. La preservación del agua y su utilización racional son un deber para el Estado y la sociedad». De este enunciado sin embargo solo se extrae como obligación concreta la de un uso racional impuesto no solo al Estado sino a la sociedad y también la preservación del agua ya existente, lo cual admite ser entendido tanto como un deber de preservación de la calidad del agua que debe comportar su saneamiento, como un deber de preservación de la cantidad de agua existente promocionando su uso racional.

Ahora bien, el modo en que está formulado el derecho al agua en ambas Constituciones puede considerarse un reflejo del embrionario estado dogmático en que se encuentra el desarrollo del contenido de derechos emergentes como el derecho a la alimentación, a la vivienda o al agua. Se requiere por tanto una tarea de delimitación y de concreción hermenéutica que precise los contornos de este derecho. En efecto, a la vista de la estructura del derecho al agua, surgen interrogantes que requieren un esfuerzo dogmático que sirva para dilucidar su alcance.

Cabe en este sentido dudar de si estamos ante un verdadero derecho o si en realidad lo que se garantiza es un servicio público que a través de un sistema de recursos puede acabar con la condena de la Administración pública, lo cual en su caso no garantiza que los niveles exigidos de abastecimiento sean reales y efectivos. Ninguno de los enunciados en ambas Constituciones es claro respecto a si existe la prohibición de que se pueda privar a nadie del suministro de agua potable para sus necesidades esenciales.

${ }^{68}$ Entre ellos el derecho el derecho a la vida, a la dignidad y a la integridad física (arts. 22 y 23), el derecho al domicilio, a las comunicaciones privadas y a la libre circulación (art. 24), el derecho a no perder la nacionalidad y no ser extraditados o exiliados (art. 25), el derecho de asilo (art. 26), garantías jurisdiccionales (arts. 27-30), la libertad de manifestación del pensamiento, el derecho a la información y la libertad académica y de investigación científica (arts. 31-33), los derechos políticos (arts. 34-37).

${ }^{69}$ De segunda generación cabe citar el derecho a la salud (art. 38), el derecho a la instrucción (art. 39), el derecho al trabajo (art. 40) y el derecho de propiedad (art. 41), y el derecho a la cultura y a la libertad artística (art. 42).

${ }^{70}$ Entre estos han obtenido reconocimiento constitucional el derecho al deporte (art. 43), el derecho al agua (art. 44), el derecho a un medio ambiente sano y equilibrado, derechos de la mujer (art. 46), la infancia (art. 47) y de los discapacitados (art. 48). 
Esta objeción en cuanto al contenido del derecho al agua garantizado tiene especial virtualidad en el caso del impago de facturas del consumo del agua o del suministro. La garantía de un suministro de agua en este tipo de situaciones debería correr a cargo de los correspondientes servicios sociales. Como modelo a seguir puede proponerse el planteado en Francia, donde se establece en el art. 28.3 de la Ley n. ${ }^{\circ} 2013-312$, de 15 de abril de 2013 que «el servicio de facturación del agua puede proceder al abono de ayudas para el acceso al agua para hogares con dificultades de pagos de sus facturas de agua por insuficiencia de recursos». En Francia no obstante existen propuestas para que «en caso de impago de la factura de agua o de suministro, el proveedor contactará imperativamente a los servicios sociales. Se prohíbe todo corte si el usuario se encuentra de buena fe en la imposibilidad de pagar una factura siempre y cuando haya quedado acreditada la situación de precariedad bien por el servicio social bien por la atribución de una ayuda social mediante decreto ${ }^{71}$. De manera análoga, el suministro no debería quedar interrumpido cuando el afectado no es un particular sino una empresa o servicio público, disponiéndose para esta situación que «la interrupción de la alimentación de agua potable de los edificios destinados al alojamiento colectivo o a la prestación de servicios de salud, no puede ser aplicada hasta que dichos edificios no hayan sido evacuados $»^{72}$.

\section{EL MARCO INSTITUCIONAL DE LA GESTIÓN, PLANIFICACIÓN Y EXPLOTACIÓN DEL USO DEL AGUA}

\section{Marruecos}

El abastecimiento es competencia de los municipios según la Carta Municipal, si bien en la práctica el servicio del agua está confiado por delegación a los operadores del agua (ONEP, régies, operadores privados y municipios directamente). Hay por tanto 4 categorías de operadores en Marruecos: las sociedades concesionarias (38\% de la población urbana), sociedades municipales (régies, en un 31\%), el operador nacional ONEP (28\%), y los municipios directamente (3\%). Según el art. 39 de la Carta Municipal de 1976, modificada en 2002 y en 2008, los servicios públicos como el abastecimiento de agua, el saneamiento y la electricidad son competencia de los municipios. La reforma de 2008 permite a los

\footnotetext{
${ }^{71}$ Art. 11 b) de la Proposition du Groupe de travail conjoint Coalition Eau - France Libertés, 2012

72 Ibid., art. $11 \mathrm{c})$.
} 
municipios agruparse para transferir la competencia del abastecimiento y saneamiento del agua creando agrupaciones de aglomeraciones urbanas.

Por contra, las asociaciones de usuarios, creadas por la ley n. ${ }^{\circ} 2-84$ sobre asociaciones de usuarios de aguas agrícolas y de aprobación de su modelo de estatutos, son un modo de gestión muy extendido en el medio rural pues gestionan aproximadamente el cuarenta por ciento de los sistemas de alimentación de agua potable de los que existen once $\mathrm{mil}^{73}$. Las asociaciones de usuarios son elegidas por la población rural en una asamblea general y garantizan el funcionamiento mediante la contratación de agentes de explotación del servicio de agua.

Los órganos autónomos estatales con competencia el abastecimiento de agua potable y el saneamiento son por una parte la administración hidráulica dependiente del Ministerio de Obras Públicas, que asegura la responsabilidad del abastecimiento de agua a escala de cuencas hidráulicas, mediante el estudio y explotación de los recursos hidráulicos y por otra parte, la Oficina Nacional de Agua Potable (Office National de l'Eau Potable, ONEP), que es un organismo dependiente del ministerio de Obras Públicas y tiene por misión controlar la distribución de agua en el medio urbano de acuerdo con las sociedades municipales (régies), y en algunos municipios rurales. Entre sus funciones figura programar, construir y gestionar las instalaciones de tratamiento y transporte de fuentes primarias de la administración hidráulica, es decir los reservorios y canales primarios ${ }^{74}$. Sin embargo de cara al consumidor, su función más relevante es la tarifa que cobra a cada sociedad municipal por la conducción del agua hasta la entrada al municipio. Esa tarifa varía de una ciudad a otra según la escasez de agua del entorno, de forma que por ejemplo la tarifa que la ONEP factura a los municipios más al sur, próximos al Sáhara, es siete u ocho veces más elevada que la de otros municipios ${ }^{75}$.

Existen 16 régies autónomas intermunicipales de agua bajo tutela en este caso del Ministerio del Interior y supervisadas por el Director de Régies y de Servicios que es a quien compete su concesión y que se encargan de la distribución de agua a las principales ciudades. Los órganos proveedores de las Régies comunales son

${ }^{73}$ La creación de este tipo de asociaciones fue exigido por los fondos de inversión en los años noventa. $C f r$. Jeanne Riaux, «Place des associations d'usagers de l'eau agricole dans la dynamique des institutions. L'exemple de la vallée des aït bou guemez dans le Haut Atlas central, Maroc», en Gestion Comparée de Bassins Versants Montagnards et Dynamiques Sociales et Institutionnelles Montpellier: IRD, 2002, p. 118.

${ }^{74} \mathrm{Cfr}$. A. El Menouar, Aspects institutionnels et reglementaires des ressources en eau au Maroc, op. cit., p. 68.

${ }^{75}$ Cfr. H. TAZI SAdeq, Du Droit de l'eau au droit à l'eau au Maroc et ailleurs, op. cit., p. 287. 
la ONEP (Office National de l'Eau Potable) y la ONE (Office National d'Electricité). La obligación de la régie es asegurar la continuidad del servicio público y pagar las tarifas de adquisición a estos dos organismos. En la producción de agua potable en torno al $80 \%$, corresponde a la ONEP; y el 20\% restante es producida por las Régies Autónomas de Distribución (RAD) que asumen también en parte la distribución del agua en el país. Otra parte de esa distribución es asumida por conjuntos de municipios y por empresas privadas.

El Ministerio de Salud Pública se encarga de controlar junto a la ONEP la calidad de los recursos hídricos para las redes de agua potable de los municipios a los que garantiza el abastecimiento. Tras su creación, la ONEP ostenta una posición de casi monopolio para la producción de agua potable ya que se corresponde con los 4/5 del volumen total nacional ${ }^{76}$. La ONEP ha puesto en marcha un programa en materia de abastecimiento que abarca hasta 2017, con la financiación de subvenciones estatales y la introducción de una tasa de saneamiento sobre el volumen de agua producido (con un canon uniforme de 1.5 dirhams el $\mathrm{m}^{3}$ ), así como una subtasa de saneamiento en los municipios en los que la oficina interviene. Se trata del órgano que debe dar efectividad al acceso al agua potable, si tenemos en cuenta que entre sus competencias figura la de asegurar la distribución del agua potable por cuenta de los municipios que formulan la demanda; también la de generalizar el acceso al agua potable especialmente en el mundo rural deficientemente equipado; desarrollar las redes de saneamiento y controlar la calidad de las aguas producidas y distribuidas.

Las Régies municipales son sociedades municipales de gestión de los servicios que si bien son personas jurídico públicas ${ }^{77}$, por su objeto social estos establecimientos actúan en las relaciones comerciales sometidas al derecho privado. Estas sociedades municipales son establecimientos públicos dotados de personalidad jurídica y de autonomía financiera a los que los ayuntamientos confían la gestión de un servicio público de interés general mediante la autorización de explotación de bienes y equipos ya existentes. Existen en la actualidad cinco ciudades gestionadas por operadores privados, 13 gestionadas por régies autónomas, 30 por régies municipales no especializadas y 500 municipios cuya gestión del agua está confiada a la ONEP (Oficina Nacional del Agua Potable).

${ }^{76}$ Los otros proveedores de agua potable son tres: la Oficina Cherifiana de Fosfatos, la mina de carbón Jerrada y Amendis-Sociedad Marroquí de Distribución del Agua, de Gas y de Electricidad del Norte de Tetuán (sociedad de derecho privado).

77 Gozan de autonomía financiera para la gestión de un servicio público local (SPL) de carácter industrial y comercial y son creadas bien por decisión del Pleno municipal o por el comité del consorcio de municipios de acuerdo con las condiciones que establece el Decreto n. ${ }^{\circ}$ 2-4-394 de 29 de septiembre 1964. 
Del examen del marco jurídico del dominio público así como los pliegos de condiciones (cahiers des charges) para la distribución de agua potable y la alimentación de energía eléctrica se deriva que forman parte de la régie: «todas las obras, tanques, edificios, terrenos, canalizaciones, contadores, máquinas y aparatos de la distibución de agua, ejecutados, instalados o adquiridos». Además la régie incopora a su activo los bienes que integran el dominio público ${ }^{78}$.

El marco jurídico de la privatización mediante operadores se rige por la ley sobre gestión delegada n. ${ }^{\circ} 54.05$ de 2005 , que la define como «un contrato por el que una persona jurídica de derecho público denominado el «delegante», delega por una duración limitada la gestión del servicio público de naturaleza económica de su competencia, a una persona jurídica de derecho público o privado, denominado el delegatario», reconociéndole el derecho de exigir una remuneración de los beneficiarios o bien obtener beneficios de esa gestión». Ahora bien, en Derecho marroquí no hay referencia a una remuneración sustancial al precisar el art. 24 de la ley que «el delegatario gestiona el servicio público por su cuenta y riesgo y como un buen padre de familia». En cambio, en Derecho francés se prevé que «la remuneración del delegatario esté sustancialmente ligada a los resultados de explotación del servicio». En consecuencia, mientras que en el mercado de servicios públicos la contrapartida remuneradora es cierta y figura en el presupuesto de la colectividad, en cambio en la gestión del servicio público la parte esencial de ingresos del operador procede de los resultados de explotación del servicio público ${ }^{79}$.

La delegación de servicio público puede además ser entendida como una modalidad de asociación de lo público y lo privado, en la medida en que el municipio como autoridad delegante conserva las prerrogativas del poder público, como el control, la organización y la propiedad de las infraestructuras. El

78 A tenor del art. 2. e) de la ley del agua n. ${ }^{\circ} 10-95$ se desprende que «forman parte del dominio público hídrico a los efectos de la presente ley»: «Los diques, presas, acueductos, canalizaciones y conducciones de agua; y las afectadas a un uso público para la alimentación de agua de los centros urbanos y las aglomeraciones rurales». El dahir de 19 de octubre de 1921 relativo al dominio municipal dispone que «forman parte del dominio municipal (....), las aguas destinadas a la alimentación de la ciudad así como las canalizaciones, acueductos, depósitos de agua y otras instalaciones que forman parte del dominio público marroquí». El dahir relativo al dominio público de las comunidades rurales (de julio de 1954) establece que se comprenden en él a efectos del decreto «las aguas destinadas a la alimentación humana (...), así como las obras destinadas a dicho uso». En su condición de bienes de dominio público todo este patrimonio forma parte igualmente de los bienes que el dahir de 1 de julio de 1914 prescribe que «no pueden ser poseídos privativamente por estar a disposición de todos».

79 Cfr. Mohammed Amine Benabdallah, «La gestion déléguée du service public au Maroc», REMALD, 2010, n. ${ }^{\circ}$ 92, p. 11. 
municipio delega por tanto en el operador privado la responsabilidad de ejecución del servicio de agua potable en el marco de un contrato de duración determinada y a cambio de una remuneración. La autoridad delegante dispone de un poder general de control económico, financiero y técnico sobre el delegatario, así como sobre la gestión de los servicios delegados inherentes a las obligaciones derivadas del contrato. En materia de suministro del agua potable, el delegatario tiene que asegurar la regularidad y la seguridad del abastecimiento y garantizar la calidad bacteriológica del agua. Está obligado a cumplir ciertos requisitos técnicos especialmente en cuanto a los rendimientos de las redes, las tasas del servicio, la capacidad de almacenamiento del agua y en principio proporcionar acceso a la red a los abonados de rentas más modestas. Sin embargo, la duración de los contratos de delegación de gestión de agua ha venido siendo tan amplia, que se ha asimilado a un monopolio de facto de las sociedades municipales (régies).

Las Agencias de cuenca desempeñan por su parte una función de concertación en la que toman parte también el Consejo Superior del Agua y del Clima y las Comisiones prefectorales y provinciales del agua. Las Agencias de Cuenca no obstante no han operado siempre en todo el territorio, de hecho hasta 2002 solo funcionaba la Agencia de Cuenca de Oum er-Rbia (en Beni Mellal), como experiencia piloto ${ }^{80}$.

A pesar de que la gratuidad de la extracción de agua de la que se benefician los organismos públicos (ONEP, ONE, ORMVA) ha quedado derogada teóricamente, este principio no se aplica en la práctica ya que lo previsto inicialmente se ha ido posponiendo de modo que las Agencias de Cuenca todavía están subvencionados por el Estado.

Las obligaciones de distribución del agua potable que se imponen a las sociedades de Derecho privado en los contratos de gestión delegada de distribución del agua comprenden la regularidad y la seguridad de alimentación y garantía de la calidad bacteriológica del agua, la mejora de los rendimientos de las redes, la mejora de las tasas de desierto, el mantenimiento de la reserva global de vecindad de 24 horas, la realización de programas de abastecimientos sociales y la conexión del conjunto de barrios urbanizados. Sin embargo, se constata una falta de mecanismos de gestión a disposición de los entes locales para la negociación y seguimiento de estos contratos a nivel local.

${ }^{80}$ Las Agencias de Cuenca tienen el carácter de establecimiento público de carácter administrativo, dotadas de personalidad jurídica y autonomía financiera y dirigido por un consejo de administración en el que además de las administraciones afectadas, están representados los usuarios y cargos representativos. 
La Dirección de Régies y de Servicios Concedidos (DRSC), del Ministerio del Interior tiene la misión del seguimiento de las operaciones de las régies y la supervisión de los contratos de gestión delegada con los concesionarios privados. A su vez, la Dirección General de Colectividades Locales del Ministerio del Interior (DGCL), a través de su Dirección del Agua y del Abastecimiento (DEA), desempeña un papel de apoyo y consejo a las colectividades en lo que se refiere a la gestión de servicios públicos.

Los walis y gobernadores presiden los consejos administrativos de las régies autónomas de distribución del agua y se consideran de hecho como los primeros responsables de la gestión del servicio del agua en las provincias. El Dahir de 6 de octubre de 1993 hace del gobernador el «coordinador de actividades de servicios y administraciones centrales del Estado y el presidente del comité técnico de la prefectura o provincia». Asimismo el gobernador tiene atribuida la competencia de intervenir para asegurar un abastecimiento suficiente de agua potable y puede velar por un uso racional del agua y por su protección contra toda forma de degradación.

Se constata por tanto en el diseño institucional marroquí de gestión del agua una fragmentación de responsabilidades que se presenta en numerosas ocasiones como un obstáculo a una gestión integrada ${ }^{81}$. A ello se añade que organismos como las siete agencias de cuenca (Agences de Basssin Hydraulique, ABH) disponen tan solo de menos de una decena de agentes para una extensión de vigilancia de $27.000 \mathrm{~km}^{2}$.

\section{Túnez}

A nivel institucional el Ministerio de Agricultura es el responsable de la política del agua mientras que el ministerio de equipamiento y ordenación del territorio tiene encomendada la política de saneamiento. Además dos operadores públicos se encargan de la distribución del agua (la Sociedad Nacional de Explotación y Distribución de Aguas SONEDE, empresa pública creada en 1968) ${ }^{82}$ y la Oficina Nacional de Saneamiento se ocupa del saneamiento (ONA), un con-

${ }^{81}$ Cfr. A. El Menouar, Aspects institutionnels et règlementaires des ressources en eau au Maroc, op. cit., p. 68.

82 Con anterioridad la sociedad estatal se denominaba Régie económica del Estado, creada en 1947 para la construcción de infraestructuras, y la ejecución de programas de prospección y movilización de recursos, especialmente orientada a abastecer los núcleos urbanos que entonces recibían un éxodo rural masivo. 
sorcio que mayoritariamente pertenece a la familia real marroquî ${ }^{83}$. La SONEDE, tiene entre sus competencias la producción, el tratamiento y la distribución del agua potable en todo el territorio, pero principalmente las ciudades, ya que solo llega al 49,7\% de zonas rurales. En el resto del territorio rural operan los denominados Grupos de Desarrollo Agrícola (GDA) que son los que garantizan en teoría la distribución en las zonas que no cubre la SONEDE. La ONA se encarga de colectar y tratar las aguas usadas y no cubre las zonas rurales, lo cual supone una gran carencia en el acceso a los servicios de agua potable. Por su parte, el Consejo Nacional del Agua, creado en 2010, tiene como misión asistir al Ministro de Agricultura, especialmente en la definición de principios generales de movilización y de valorización de la utilización de recursos hídricos y está presidido por el Ministro de Agricultura. Se trata de un órgano consultivo y estratégico, integrado por los representantes de varios ministerios, empresas y organizaciones nacionales.

Sin embargo, el mayor problema que tiene Túnez es que la actuación de estas instituciones es muy desigual a nivel territorial. Catorce provincias (incluidas 9 provincias costeras) tienen una tasa de abastecimiento muy por encima de la media. Este dato geográfico revela una discordancia clara y evidente en la distribución espacial de los recursos puesto que en diez provincias que acaparan casi el $62 \%$ del agua movilizada, la tasa de abastecimiento es inferior a la media nacional. Este es el caso de las provincias del Centro-Oeste, Noroeste y Bizerta. A pesar de ello el sistema centralizado de planificación de recursos ha evolucionado con el curso de los años hacia una gestión algo más descentralizada, especialmente a partir de los años noventa, para tener en cuenta las especificidades locales y regionales, de forma que los diferentes programas hidráulicos han sido elaborados no solo a propuesta de la SONEDE y las ONA, sino también por los gobiernos provinciales y los Comisariados Regionales para el desarrollo Agrícola (CRDA) ${ }^{84}$. La función que cumple en este nuevo contexto el Ministerio de Agricultura es el de controlar las prioridades en función de los intereses generales y armonizar los programas a nivel regional y nacional según los recursos financieros disponibles. El Ministerio de Agricultura se encuentra asistido del Consejo Nacional del Agua y de la Comisión Nacional del Agua. El primero es un órgano consultivo que emite recomendaciones sobre los proyectos de planes nacionales. En cuanto a la Comisión, tiene como cometido emitir opiniones técnicas sobre la gestión hidráu-

\footnotetext{
${ }^{83}$ Cfr. Annabelle Houdret, Les conflits autour de l'eau au Maroc: origines sociopolitiques et écologiques et perspectives pour une transformation des conflits, op. cit., p. 39.

${ }^{84}$ Cfr. Mustapha Besbes, James Chaehd, Abdelkader Hamdane, Securité Hydrique de la Tunisie, L'Harmattan, Paris, 2014, p. 87.
} 
lica. A nivel regional, los Comisariados Regionales para el desarrollo Agrícola (CRDA) coordinan la política agrícola en su territorio. La SONEDE se encarga del abastecimiento de agua potable de las zonas urbanas y algunas aglomeraciones rurales, de forma que abastece el agua no solo para el uso doméstico, sino también para el uso colectivo, industrial y turístico. La SONEDE dispone de sus delegaciones regionales, por lo que escapa al control de los CRDA. Por su parte, la Sociedad de Explotación de Canales de Abducción de Aguas del Norte (SECADENORD) se encarga de las extracciones y trasvase de agua del Norte hasta el Centro, abasteciendo de agua a la SONEDE y a algunos CRDA.

La otra estructura institucional en la gestión del agua son los Grupos de Desarrollo Agrícola (GDA) que provienen de otra figura de organización colectiva de usuarios del agua que tenía por nombre el de Grupos de Interés Hidráulico, a su vez herederos de las Asociaciones de Interés Colectivo ${ }^{85}$. La Ley n. ${ }^{\circ}$ 99-43 de 10 de mayo de 1999 permitió la extensión de los GIH a otras actividades de desarrollo agrícola, pasando a convertirse en GDA. Sin embargo, a pesar de su extensión por todo el territorio, los GDA han encontrado dificultades de todo tipo entre las que sobresale el intervencionismo estatal y su falta de financiación ${ }^{86}$.

En cuanto a la salubridad del agua, es fundamental también la intervención del Ministerio del Medio Ambiente, del que dependen la Oficina Nacional de Saneamiento (ONA) y la Agencia Nacional de Protección del Medioambiente. La primera es el principal agente en la depuración del agua urbana, mientras que la segunda se encarga de la lucha contra la contaminación y degradación de los recursos.

A nivel institucional siguen sin embargo existiendo lagunas, como ocurre con el Consejo Nacional del Agua, previsto por el Código de Aguas, ya que raras veces se solicita su opinión o su aprobación de los programas hidráulicos, ni tampoco se abre dicha planificación a consulta pública a escala nacional o regional ${ }^{87}$.

\section{LAS DIFICULTADES EN LA EFECTIVIDAD DEL DERECHO AL AGUA TRAS LAS NUEVAS CONSTITUCIONES}

\section{Marruecos}

La legislación adoptada tras la promulgación de la nuevas Constituciones ha pretendido adaptar al nuevo dictado constitucional el marco normativo del acce-

${ }^{85}$ Decretos 87-1261 y 87-1262, de 27 de octubre de 1987, y Decreto 88-150, de 12 de enero de 1988.

${ }^{86}$ M. Besbes, J. Chaehd, A. Hamdane, Securité Hydrique de la Tunisie, op. cit., p. 105.

${ }^{87}$ Ibid., p. 89. 
so al agua. En Marruecos, tras la nueva Constitución persiste la gran disparidad de precios entre las distintas ciudades y regiones marroquíes ${ }^{88}$. La explicación de estas diferencias cabe atribuirla al modo de gestión adoptado en cada zona según la gestión esté atribuida a empresas concesionarias o bien a las empresas públicas.

En Marruecos la nueva ley del agua 36-15, promulgada por el Rey en agosto de 2016, se refiere al derecho al agua en su art. 2 como aquel que permite satisfacer las necesidades fundamentales en el respeto de la equidad según las condiciones previstas en la propia ley. En particular el desarrollo legislativo del derecho constitucional al agua exige la salubridad del agua, que ha sido impuesta por vía legislativa en el art. 49 de la nueva Ley 36-15, lo que exige que el agua de uso alimentario debe ser potable, remitiendo al reglamento para definir el estándar de potabilidad y salubridad. En conformidad con ello, el art. 50 prohíbe proponer, vender o distribuir, bajo cualquier forma, para la alimentación humana un agua no potable, al igual que se prohíbe utilizar aguas que no respondan a los estándares de salubridad para la preparación o conservación de alimentos. Sin embargo, el propio art. 50 dispone que en caso de necesidad ligada a la composición natural del agua y a la ausencia de otra alternativa o en caso de fuerza mayor la Administración puede bajo ciertas condiciones establecidas por vía reglamentaria, autorizar el uso local y temporalmente de un agua que no responda a todas las normas del art. 49 si no constituye un peligro para la salud humana.

Entre los principios que consagra esta ley figura el de la propiedad estatal del agua, el de su valor económico, el de solidaridad a todos los niveles (nacional, regional y local) en la gestión del agua. Entre sus orientaciones se encuentra el cuestionamiento de las producciones agrícolas fuertemente consumidoras de agua al depender su rentabilidad en muchos casos de las subvenciones y de protecciones tarifarias. También se ha aplicado a la política de desarrollo turístico factores como la escasez de los recursos hídricos y el coste del agua.

El Comité de seguimiento de la gestión delegada es quien aprueba las tarifas para el consumo y el saneamiento del agua además de la electricidad. En 2014 para salvar la Oficina Nacional de la Electricidad y el Agua de la quiebra, por lo que se procedió a una subida de las tarifas tras la firma de un nuevo contratoprograma entre Estado y ONEE (que integra la anterior oficina del agua con la de energía eléctrica) ${ }^{89}$. No obstante las tarifas de 2014 se han mantenido invariables en $2015^{90}$.

88 Cfr. Houria Tazi Sadeq, Du Droit de l'eau au droit à l'eau au Maroc et ailleurs, op. cit., p. 410 .

89 Arrêtés ministériels n. ${ }^{\circ} 2451.14$ et n. ${ }^{\circ} 2682.14$ publiés au Bulletin Officiel du 22 juillet 2014.

90 Arrêté ministériel n. ${ }^{\circ} 4204.15$, du 22 décembre 2015. 
Las tarifas de las régies y de la ONE se rigen por decreto ministerial que es la autoridad de tutela (el Ministerio del Interior). En cuanto a las régies sujetas a concesión, hay que estar a los términos del contrato de gestión delegada entre municipio y operadores privados.

Un reciente informe de agosto de 2016 de la comisión parlamentaria de la Cámara de Representantes de evaluación del impacto de políticas públicas en el mundo rural ha concluido que el programa de abastecimiento de agua potable en zonas rurales no se ha extendido a todo el ámbito rural. Los distribuidores se abastecen de la ONEP, que les factura un precio en función de la accesibilidad de los recursos hídricos de la régie y del grado de facilidad en su explotación (en función de si la extracción es desde embalses, fuentes, o prospecciones). De ahí también la extrema diversidad de precios entre las distintas ciudades.

\section{Túnez}

En Túnez, antes de la actual Constitución de 2014 el legislador ya acometió una tarea de actualización del Derecho de aguas mediante sucesivas reformas al Código de aguas que databa de 1975 para adaptarlo a los cambios estratégicos impuestos por los poderes públicos, como las medidas de ahorro o la búsqueda de una valoración optimizadora. En este período parecía primar más la movilización de recursos que los múltiples factores que pudieran influenciar de forma durable las demandas sectoriales ${ }^{91}$. De ahí que nuevos reglamentos en 2001 y 2002 se ocuparan de proporcionar una mejor gobernanza del agua, especialmente pretendiendo una mayor sensibilización de los usuarios hacia la preservación de este recurso. Se dio entrada de este modo a alguno de los principios vigentes a nivel internacional, tales como la noción de durabilidad del agua como riqueza nacional o la noción de utilidad pública para obras de ahorro de agua; se permitió la intervención del sector privado mediante concesiones, especialmente para la producción y utilización de recursos no convencionales en las zonas industriales o turísticas, así como se daba acogida al concepto de diagnóstico técnico (que iba a permitir un control técnico optimizador) y al de racionamiento en el consumo (mediante la tarificación especialmente).

De ahí que desde la primavera de los jazmines haya entrado en vigor un aumento de tarifas tras la publicación de un Decreto en el JORT n. ${ }^{\circ} 105$, de 31 de diciembre de 2013. La SONEDE (Société Nationale d'Exploitation de Distri-

${ }^{91}$ Cfr. Bruno Romagny, «Mutations socio-territoriales et recomposition des politiques hydrauliques: vers une gestion durable de l'eau dans le Sud-Est tunisien?», en Ali BENSAÂD (dir.), L'eau et ses enjeux au Sabara, Karthala, Paris, 2011, p. 116. 
bution des Eaux) tiene previsto alcanzar un $100 \%$ de abastecimiento para el agua potable en zonas urbanas y de un $94 \%$ para las zonas rurales. La tasa de acceso para la zona rural se ha fijado por la SONEDE en un $47 \%$.

Asimismo en Túnez la tarificación no ha hecho más que aumentar desde la apertura del proceso constituyente, ya que en 2012 se aprobó un aumento anual de la tarificación del agua potable en 4 años (2013-2016), si bien en 2015 no se aplicó. El motivo de tal aumento fue el incremento del coste del agua, ya que el coste del metro cúbico había ascendido a 820 millimes frente a los 690 por m3 del precio a los consumidores. En 2016 de nuevo se ha impuesto la línea de continuar con nuevas alzas en las tarifas de entre un 8 y un $15 \%$. En los dos primeros meses de 2015 de nuevo se han elevado las tarifas un 3,7\% $\%^{92}$. El alza de precios en las tarifas sin embargo ha sido criticada por privar a los más desfavorecidos de un recurso vital que además se agrava por la falta y degradación de las condiciones sanitarias de este sector de la población.

Tras la nueva Constitución, los aspectos institucionales del derecho al agua se han intentado acometer mediante una actualización del Código de aguas para acomodarlo a los arts. 12, 13, 44 y 45 de la nueva Constitución de enero de 2014. La proyectada reforma del código de aguas que data de 2012 y sigue pendiente a comienzos de 2017, pretende retomar y consolidar el estatuto jurídico del agua al considerarlo bajo todas sus formas un bien de dominio público. Por tanto el agua debe seguir siendo un bien común pero ahora el acceso al agua potable es un derecho fundamental, lo que quiere decir que el poder público debe asegurar a todos los tunecinos un abastecimiento suficiente, físicamente accesible y a un coste asequible, de un agua salubre y de calidad aceptable para el uso personal y doméstico. Ello obligará a determinar cuál es la cantidad suficiente, pero también deberá garantizar una mejor protección de todos los recursos hidráulicos mediante medidas represivas y preventivas o de control. En particular, será necesaria una norma nacional sobre la calidad del agua equivalente a las normas de la Organización Mundial de la Salud, ya que hasta ahora ninguna norma obligatoria es oponible a los distribuidores de agua potable en Túnez.

92 El alza para el primer tramo de la tarifa ha sido de 133 millimes, por mes y familia, situado en un consumo de entre 0 y $20 \mathrm{~m}^{3}$ por trimestre. Este tramo de tarifa representa el $40 \%$ de la clientela de la SONEDE. Se ha aplicado un incremento de 300 millimes por mes y familia (10 millimes por día) a los consumidores situados en el tramo entre 21 y $40 \mathrm{~m}^{3}$ por trimestre, lo que representa el $31 \%$ de los abonados. El tercer tramo de la tarifa ha aumentado en 517 millimes por mes y familia (17 millimes por día) para los consumidores situados entre un consumo entre los 41 y $70 \mathrm{~m}^{3}$ al trimestre. Este tramo de consumo representa el $20 \%$ de la clientela. La categoría de consumidores de gran consumo, que representa $9 \%$ de los abonados, es objeto de un aumento mensual de la tarifa que va de los 1.300 millimes y 5.725 millimes. 
Se debe abordar también la reforma del Decreto n. ${ }^{\circ} 73-515$, de 30 de octubre de 1973, de aprobación del Reglamento de pago del agua, para autorizar a los arrendatarios y ocupantes de buena fe a beneficiarse del derecho de pago igual que si fueran propietarios, a prohibir el corte de agua a iniciativa del propietario del local en alquiler siempre que éste esté habitado, y se ha puesto en marcha una nueva clasificación de las tarifas del agua en función del tipo de abonado al servicio y en función del destino del inmueble (tarifa comercial, industrial, administrativo, profesión liberal, etc.) y ello para permitir un nuevo sistema de tarificación que aplica la tarifa subvencionada del agua solo para el uso doméstico en hogares, pagando el resto de usuarios el agua potable a su precio real que es el coste del metro cúbico.

$\mathrm{Al}$ igual que la jurisprudencia francesa, en el Derecho tanto marroquí como tunecino, el usuario de un servicio público de carácter comercial recibe el mismo tratamiento que en una relación de derecho privado. De ahí que no se admita el recurso por exceso de poder ante la jurisdicción administrativa contra los actos administrativos que prohíban acceder a un servicio público ${ }^{93}$. Del mismo modo, los daños que pueda sufrir el particular como candidato a usuario pertenecen al derecho privado y a su jurisdicción.

Aun siendo cierto que las relaciones entre el servicio público comercial y el usuario son de Derecho privado, los actos reglamentarios dictados por los órganos de tutela competentes para definir las condiciones de acceso de los usuarios al servicio tienen el carácter de una aplicación de criterios orgánicos de actos administrativos. En concreto, entran dentro de esta categoría todo lo relativo a las condiciones del funcionamiento del servicio, de los cánones a cargo de los usuarios, el montante de la participación de la conexión a la red, las tarifas de alquiler de los contadores o las condiciones de instalación. Dicho carácter los convierte en susceptibles de control por la jurisdicción administrativa.

Parece que un eventual control de constitucionalidad debería incidir en la tarificación del agua según el nivel de renta. Sin embargo, siendo esta cuestión

${ }_{93}$ En Marruecos no obstante hay jurisprudencia aislada que ha sostenido que es exigible la responsabilidad a los poderes públicos en litigios que oponen a terceros víctimas de un accidente causado por servicios públicos como el ferrocarril (Sentencia del Tribunal superior Administrativo de 17 de abril de 1977, O. N. C. F. c. Kbira Bent Kacem), en aplicación del art. 79 del DOC (Código del Derecho de Obligaciones y Contratos de 12 de septiembre de 1913 modificado por Ley n. ${ }^{\circ}$ 53-05), que regula la responsabilidad patrimonial de las Administraciones por los daños producidos por el funcionamiento de sus órganos o por culpa de sus agentes frente al art. 88 de ese mismo texto, que regula la responsabilidad entre particulares. $C f r$. Michel Rousset y Mohammed Amine Benabdallah, Contentieux administratif marocain, Publications de la REMALD, Rabat, 2014, p. 129. En Túnez es el art. 84 del DOC el que contempla la responsabilidad de la Administración por hechos o faltas imputables a sus funcionarios. 
dejada a los reglamentos, se aventura harto difícil. Además de ello, la influencia de la tarificación sobre el consumo puede considerarse modesta todavía en ambos países, dado que el nivel de consumo per capita se mantiene dentro de unos niveles no muy altos, lo que comporta que en los hogares más desfavorecidos no hay margen para subir las tarifas, de ahí que el precio del agua siga siendo módico ${ }^{94}$. Ahora bien, no favorece la equidad en la tarificación el uso de sistemas de contador aproximativos, al usar contadores colectivos en muchos inmuebles. En Marruecos el art. 9 del Decreto n. ${ }^{\circ}$ 2-97-414 de 4 de febrero de 1998 relativo a las modalidades de fijación y de cobertura del suministro de utilización del agua del dominio público hidráulico (vigente hasta en tanto no se dicten los textos de aplicación de la nueva Ley 36-15 de 10 de agosto de 2016) penaliza el funcionamiento defectuoso de los contadores, al imponer sanciones diferentes, según si el funcionamiento defectuoso es comunicado por el usuario o si es detectado por la Administración. En el primer caso se da un plazo al usuario para que costee la reparación y si incurre en retraso se le aplica una sanción de 10 céntimos por $\mathrm{m}^{3}$ para el $50 \%$ del volumen de agua autorizado. Si la reparación no tiene lugar o tiene lugar fuera del segundo plazo se procederá al corte del suministro. En la segunda hipótesis, si el funcionamiento defectuoso es comunicado por la Administración, procederá al corte del suministro si la reparación no tiene lugar en el plazo de 60 días, aplicando la misma sanción de 10 céntimos por $\mathrm{m}^{3}$ de la mitad del volumen desde 1 de marzo a 30 de noviembre si el defecto era difícil de detectar y si es manifiesto se aplica esa misma sanción desde el último recibo. En Túnez se exige que cada local debe estar provisto de un contador. Sin embargo, en ciertos inmuebles los datos de consumo se registran en un contador general, lo cual no permite a los usuarios conocer su consumo real y por tanto economizar agua. Además se han detectado numerosas fugas especialmente en equipamientos e instalaciones sanitarias que tiene partes comunes que no son reparadas con la diligencia necesaria. De ahí que en Túnez la SONEDE ofrezca la posibilidad de pagos del coste de la instalación de contadores individuales en varios plazos trimestrales que se pueden alargar hasta un máximo de 8 años.

Aun así los mayores desafíos para la efectividad del derecho al agua en ambos países no parecen derivar de la falta de una legislación adecuada y garantista de este derecho, sino en la ineficacia de su aplicación en materia de infracciones por falta de reglamentos adaptados a los distintos ámbitos de la utilización del agua y de los mecanismos para su aplicación ${ }^{95}$. Asimismo, sigue estando pendiente el

\footnotetext{
94 Cfr. Jean-Jacques Pérennès, L'eau et les hommes au Maghreb, Karthala, op. cit., p. 248.

95 Para un desarrollo de este planteamiento vid. Allal El Menouar, Aspects institutionnels et reglementaires des ressources en eau au Maroc, op. cit., p. 67.
} 
desarrollo de una solidaridad regional efectiva en la gestión y utilización del agua entre las distintas zonas de ambos países. Ello se encuentra conectado a la existencia todavía de un déficit en la movilización de los recursos hídricos que puede amenazar un desarrollo sostenible en ambos países. En este sentido resulta positivo el impulso que han cobrado los proyectos de infraestructuras gracias a los fondos de inversión de países del Golfo, en especial con la construcción de nuevos embalses en ambos países.

Existe en ambas Constituciones margen para que el desarrollo y la efectividad del derecho al agua se traduzcan en una directriz de asunción de costes a la vez colectiva e individual según los principios de responsabilidad y de utilidad. En este sentido, los costes asociados a la captación, producción, almacenaje, distribución, utilización, conservación y reciclaje del agua deben ser socializados si realmente se quiere garantizar que el acceso al agua se haga en la cantidad y en la calidad que se consideran como el mínimo vital necesario e indispensable. Pero a los costes mencionados se deberían añadir las externalidades negativas que no son absorbidas por los precios del mercado y que de este modo se asumirían colectivamente. En esta línea, gracias a las ayudas del Banco Mundial los operadores concesionarios del servicio han puesto en marcha conexiones al agua de carácter social con facilidades de pago y con un montante en función de la distancia a la red ${ }^{96}$. La conexión a la red viene siendo un coste inicial que para una gran parte de la población supone varias mensualidades de un sueldo medio.

De igual modo, para dotar de mayor efectividad a este nuevo derecho constitucional se deberían instaurar controles públicos más efectivos sobre los operadores privados y sus relaciones con los usuarios con miras a que la ejecución de los contratos de gestión delegada estén supeditados al bien colectivo. Precisamente el recurso por los operadores privados a empresas externas de recaudación suele dejar sin agua a miles de ciudadanos sin recursos por impago de las facturas. Por otra parte, el fortalecimiento de las instituciones públicas y el aprovechamiento de su know-how acumulado en el manejo del complejo sistema de agua debiera ser el punto de partida para una rápida transición del enfoque de gestión de mando y control adoptadas anteriormente y que ha llegado a su límite, a un enfoque de manejo adaptativo a los recursos; lo cual también implica promover soluciones locales.

${ }^{6}$ Cfr. Claude Miras et Xavier Godard, «Les firmes concessionnaires de service public au Maroc: Eau potable, assainissement et transports collectifs», Meditarrenée, núm. 106/2006, p. 117. 
Title:

The right to water in the new Constitutions of morocco (2011) and tunisia (2014).

\section{Summary:}

I. Introduction: the right to water in a compared perspective. II. The nature of the right to water as an emerging right. III. The progressive removal of muslim law as a legal regime of water basis in morocco and tunisia. IV. The peculiarities of the law of waters in tunisia and morocco. 1. Morocco. 2. Tunisia. V. The tariff of the supply service as a tool for respect to the content of right to water. 1. Tariffs in morocco prior to the new constitution. 2. Tariffs in tunisia before the constitutionalization of the right to water. VI. The recognition of the right to water in the new constitutions of morocco (2011) and tunisia (2014). VII. The institutional framework of the management, planning and exploitation of the use of water. 1. Morocco. 2. Tunisia. VIII. Difficulties in the effectiveness of the right to water after new constitutions. 1.1 Morocco. 2. Tunisia.

\section{Resumen:}

El régimen jurídico del agua en Marruecos y Túnez sigue siendo todavía a día de hoy un compuesto de legislación y costumbres pero en el que el Derecho musulmán ha ido retrocediendo ya que ambos países procedieron a desarraigar el régimen del agua del Derecho musulmán al no contemplar en su legislación referencias al derecho musulmán como fuente del derecho a diferencia de lo que ocurre en otros sectores del Derecho de bienes.

En Marruecos el contenido constitucionalmente garantizado del derecho al agua parece limitarse al igual acceso a este recurso natural. Se trata de un mandato que no se ha sido configurado como una obligación de resultado, dado que el encabezado del art. 31 de la Constitución marroquí mandata a que se movilicen recursos por parte de los poderes públicos, lo que supone una obligación de hacer que debe orientar las políticas públicas. Del art. 44 de la Constitución de Túnez solo se extrae como obligación concreta la de un uso racional impuesto no solo al Estado sino a la sociedad y también la preservación del agua ya existente, lo cual admite ser entendido tanto como un deber de preservación de la calidad del agua que debe comportar su saneamiento, como un deber de preservación de la cantidad de agua existente promocionando su uso racional.

El modo en que está formulado el derecho al agua en ambas Constituciones puede considerarse un reflejo del embrionario estado dogmático 
en que se encuentra el desarrollo del contenido de derechos emergentes como el derecho a la alimentación, a la vivienda o al agua. Se requiere por tanto una tarea de delimitación y de concreción hermenéutica que precise los contornos de este derecho. Para ello se examinará la nueva legislación promulgada tras las nuevas Constituciones.

\section{Abstract}

The legal regime of water in Morocco and Tunisia is still a composite of legislation and customs but in which Muslim law has lose ground since both countries proceeded to uproot the water regime of Muslim law by not contemplating in Its legislation references to Muslim law as a source of law unlike what happens in other sectors of property law.

In Morocco the constitutionally guaranteed content of the right to water seems to be limited to equal access to this natural resource. This is a mandate that has not been configured as an obligation of result, since the heading of art. 31 of the Moroccan Constitution mandates public authorities to mobilize resources, which implies a duty to perform that should guide public policies. From art. 44 of the Tunisian Constitution only it follows as a concrete obligation the rational use imposed not only on the State but also on society as well as the preservation of existing water, which admits to be understood both, as a duty to preserve the quality of the Water that must include its sanitation, and as a duty to preserve the existing water quantity promoting its rational use.

The way in which the right to water is formulated in both Constitutions can be seen as a reflection of the embryonic dogmatic status of content of emerging rights, such as the right to food, housing or water. It is therefore required a task of delimitation and hermeneutical concreteness in order to specify the contours of this right. This essay will examine the new proposed legislation after the new Constitutions.

\section{Palabras clave:}

Derecho al agua, Derechos emergentes, Constitución de Marruecos, Constitución de Túnez.

\section{Keywords:}

Right to water, Emerging Rights, Constitution of Morocco, Tunisian Constitution. 